\title{
Characterization of Camptothecin-induced Genomic Changes in the Camptothecin-resistant T-ALL-derived Cell Line CPT-K5
}

\author{
EIGIL KJELDSEN $^{1}$, CHRISTINE J.F. NIELSEN ${ }^{2}$, AMIT ROY ${ }^{2 *}$, CINZIA TESAURO ${ }^{2}$, \\ ANN-KATRINE JAKOBSEN ${ }^{3}$, MAGNUS STOUGAARD ${ }^{3}$ and BIRGITTA R. KNUDSEN ${ }^{2}$ \\ ${ }^{1}$ Cancer Cytogenetics Section, HemoDiagnostic Laboratory, and \\ ${ }^{3}$ Department of Pathology, Aarhus University Hospital, Aarhus, Denmark; \\ ${ }^{2}$ Department of Molecular Biology and Genetics, C.F. Mфllers Allé, Aarhus University, Aarhus, Denmark
}

\begin{abstract}
Acquisition of resistance to topoisomerase I (TOP1)-targeting camptothecin (CPT) derivatives is a major clinical problem. Little is known about the underlying chromosomal and genomic mechanisms. We characterized the CPT-K5 cell line expressing mutant CPT-resistant TOP1 and its parental T-cell derived acute lymphoblastic leukemia CPT-sensitive RPMI-8402 cell line by karyotyping and molecular genetic methods, including subtractive oligobased array comparative genomic hybridization (soaCGH) analysis. Karyotyping revealed that CPT-K5 cells had acquired additional structural aberrations and a reduced modal chromosomal number compared to RPMI-8402. soaCGH analysis identified vast copy number alterations and $>200$ unbalanced DNA breakpoints distributed unevenly across the chromosomal complement in CPT-K5. In addition, the short tandem repeat alleles were found to be highly different between CPT-K5 and its parental cell line. We identified copy number alterations affecting genes important for maintaining genome integrity and reducing CPT-induced DNA damage. We show for the first time that short tandem repeats are targets for TOP1 cleavage, that can be differentially stimulated by $C P T$.
\end{abstract}

This article is freely accessible online.

*Current address: Department of Biotechnology, National Institute of Pharmaceutical Education \& Research (NIPER), Hajipur, Vaishali, India.

Correspondence to: Dr. Eigil Kjeldsen, Cancer Cytogenetics Section, HemoDiagnostic Laboratory, Aarhus University Hospital, TageHansens Gade 2, Ent. 4A, DK-8000 Aarhus C, Denmark. E-mail: Eigil.Kjeldsen@clin.au.dk

Key Words: CPT-K5, camptothecin resistance, karyotype, aCGH, genomic instability, short tandem repeat.
The camptothecin (CPT) derivatives, topotecan and irinotecan ( $\mathrm{SN}-38$ being the active metabolite), belong to an important group of drugs used for the treatment of many types of malignancies in advanced stages, including colorectal, ovarian, small cell lung cancer and acute leukemia (1-5). However, acquired resistance to these drugs greatly compromises their efficacy in clinical use (6).

The CPTs are highly selective inhibitors of the nuclear enzyme DNA topoisomerase I (TOP1) [reviewed in (7)]. TOP1 is an important monomeric enzyme that is required to release the torsional tension of DNA introduced during the DNA replication and transcription processes in normal cells [reviewed in (8)]. Moreover, it has been shown that, in addition to its DNA-relaxing activity, TOP1 also has independent kinase activity important for splicing of premRNA (9). The enzyme exerts its relaxing activity by transiently cleaving and rejoining one strand of the DNA duplex. The CPTs are non-competitive, reversible TOP1 inhibitors that cause accumulation of TOP1-cleavage complexes (TOP1-cc) in the genome by transiently preventing the DNA rejoining step of catalysis. The trapped TOP1-cc are converted into one-ended DNA double-strand breaks (DSBs) when they collide with the DNA replication or transcription machinery. It is generally accepted that the formation and stabilization of TOP1-cc and their conversion into one-ended DSBs is a prerequisite for the cytotoxic activity of CPTs (10).

Although many players have been implicated in the cellular response to CPT, little is known about the pathways downstream of the trapped TOP1-cc that ultimately lead to repair of DNA damage or cell death. Impaired DSB repair makes cells hypersensitive to CPT and unless the DSBs are repaired they are lethal to the cell. DNA repair may lead to chromosomal or genomic alterations depending on the involved pathways. Several CPT-resistant cell lines have been derived (11-22), but only few of these have been characterized at the chromosomal or genomic level $(21,23)$. 
In the present study we aimed to characterize the chromosomal complement and global copy number aberrations generated by acquired CPT resistance in the CPT-K5 cell line to gain insight into which regions of the genome may be affected in acquisition of CPT resistance. Furthermore, we examined whether short tandem repeat (STR) sequences, normally used for paternity testing and cell line authentication, are targets for TOP1 DNA cleavage, and whether these DNA cleavage sites can be selectively stimulated by CPT.

\section{Materials and Methods}

Cell lines and cell proliferation analysis. Andoh and co-workers established the CPT-resistant cell line, CPT-K5, from its parental sensitive counterpart human T-cell derived acute lymphoblastic (TALL) cell line RPMI-8402 (wild-type) by exposure to stepwise increasing concentrations of the semi-synthetic water-soluble CPTderivative, irinotecan (11). For this study, cells stored in liquid nitrogen were thawed and cultured briefly at an initial density of $1 \times 10^{6}$ cells $/ \mathrm{ml}$ in RPMI 1640 medium supplemented with $10 \%$ fetal calf serum as described elsewhere (24). Growth inhibition of the cells by CPT was determined by counting the number of cells in culture using a hematology analyzer (Sysmex KX-21N; Sysmex Nordic Aps, Copenhagen, Denmark).

Nuclear extracts, western blotting, and measurement of tyrosyl-DNA phosphodiesterase 1 (TDP1) and TOP1 activity. Preparation of nuclear extracts from RPMI-8402 and CPT-K5 cells, TOP1-specific western blotting and TOP1 activity measurements by rolling-circle enhanced enzyme activity detection (REEAD) was performed as described previously (25), while TDP1 activity measurement was performed as described in (26).

Expression and purification of recombinant human TOP1. Recombinant human TOP1 was expressed in yeast and purified to homogeneity, as described previously (27). The enzyme preparation was tested for purity by sodium dodecyl sulfate (SDS) polyacrylamide gel electrophoresis followed by Coomassie staining and the concentration estimated by comparison to a bovine serum albumin (BSA) standard before use.

G-Banding and fluorescence in situ hybridization (FISH). Chromosomal preparations and G-banding were performed according to standard protocols as described in (28). Karyotypes and FISH results were reported according to ISCN, 2013 (29). Analysis of 10 G-banded metaphases was carried out using a Laborlux microscope (Leica, Germany) equipped with a grey-level charge coupled devicecamera and Ikaros karyotyping software implemented on a Dell Optiplex GX1 (MetaSystems, Heidelberg, Germany). Locus-specific FISH analysis of interphase nuclei and metaphase spreads was carried out with the following directly fluorescent labeled probe sets according to the manufacturers' instructions: SIL-TAL1 FISH DNA probes and TOP1/CEN20 (DAKO, Glostrup, Denmark); BlueFISH Bacterial Artificial Chromosomes (BAC) probes (BlueGnome, Cambridge, UK): RP11-133H19 fluorescence labeled with red (11p15.4, pos. 8,555,486-8,732,332 bp located telomeric to the LIM domain only 1 (LMO1) gene pos. 8,202,433-8,241,982) and RP11$298 \mathrm{I} 3$ (14q11.2, pos. $22,435,253-22,627,198$ located centromeric to the Tcrd T cell receptor delta chain (TCRD) gene pos. 21,994,08522,002,042); and custom-made BAC-based probes (Empire Genomics, Buffalo NY, USA): RP11-368G2 (4q22.1, pos. $89,137,575-89,319,451)$, and RP11-213O13 (14q32.11, pos. $89,466,687-89,648,208)$ were used for validation of array-based comparative genomic hybridization $(\mathrm{aCGH})$ results. Interphase nuclei and metaphases were counterstained with 4',6-diamidino-2phenylindole (DAPI). The genomic position of the listed BAC probes was according to National Center for Biotechnology Information (NCBI) build 36.1 (hg18) (http://www.ncbi.nlm.nih.gov).

Spectral karyotyping (SKY). Pretreatment, denaturing, and hybridization of microscopy slides with chromosome suspension applied were carried out as previously described (30) according to the manufacturer's instructions (Applied Spectral Imaging ${ }^{\mathrm{TM}}$, Migdal HaEmek, Israel). Ten fully analyzed mitoses in the SKY analysis were performed for both cell lines. Numerical and structural aberrations were counted using a normal female as reference. Karyotypes were described according to International System for Human Cytogenetic Nomenclature (ISCN) (29)

aCGH analysis. High-resolution aCGH analysis was performed using the 180k oligo-based Cancer CytoChip (BlueGnome) as described elsewhere (31). In brief, high molecular weight DNA was isolated from RPMI-8402 and CPT-K5 cells using Gentra Pure Gene kit (Qiagen AB, Sollentuna, Sweden) according to the manufacturer's instructions. Pooled female DNA (Promega, Biotech $\mathrm{AB}$, Nacka, Sweden) was used as reference DNA to determine the DNA copy number status of the female RPMI-8402 cells and derivative CPT-K5 cells. In addition, subtractive aCGH analysis of CPT-K5 was performed with isolated DNA from the parental cell line RPMI-8402 as reference DNA. The analysis was carried out according to the manufacturer's instructions using $0.5 \mu \mathrm{g}$ of DNA. After hybridization, washing and drying, the oligo arrays were scanned at $2.5 \mu \mathrm{m}$ with a GenePix 4400A microarray scanner (Molecular Devices, Sunnyvale, CA, USA). Initial analysis and normalization was achieved with BlueFuseMulti v2.6 (BlueGnome). For analysis and visualization, $\log 2$ probe signal values were imported into Nexus Copy Number software v6.1 (BioDiscovery, Hawthorne, CA, USA), and segmented using RANK segmentation algorithm with a minimum of five probes/segment. Gains and losses were defined by $\log 2$ ratios 0.16 and -0.16 , respectively, while 0.5 and -1.0 defined high copy gains and large losses, respectively. The reference genome was NCBI build 36.1 (hg18). Bioinformatics analysis was performed by querying the University of California, Santa Cruz database (http://genome.ucsc.edu).

Genomic break point analysis. Break points were defined with high precision as locations where a change in copy number occurred in called regions of amplifications and deletions as determined by the Nexus software algorithm. To quantify genomic breakage, $\log _{2}$ ratio differences larger than 0.3 were used to discriminate putative DNA breakage points. We identified those breakage points at the edges of segments of copy number gains and losses as well as points of abrupt copy number changes called within larger aberrations. The precision of this type of measurement is determined by the resolution of the array. The smallest aberration we were able to detect with confidence on the $180 \mathrm{k}$ platform was $100 \mathrm{~kb}$ in length. In addition, the abnormality needed to be present in at least $10-20 \%$ of the cells in order to be detected. 
Immunophenotyping by flow cytometry. Immunophenotyping of exponentially growing RPMI-8402 and CPT-K5 cells were carried out as described in (32).

STR profiling. STR profiling was performed at the Department of Forensic Medicine, University of Copenhagen, Copenhagen, Denmark, as part of their routine analyses using the AmpFISTR ${ }^{\circledR}$ Identifiler PCR Amplification kit (Applied Biosystems, Thermo Fisher Scientific, Waltham, MA, USA). The STR profiling was repeated twice with identical results on genomic DNA purified from two independent cultures from both cell lines.

Generation of STR TOP1 cleavage substrates. The flanking sequences in the STR TOP1 cleavage substrates were the same in the three substrates (marked below in bold) and the STR repeat length (marked with underline) were from the parental CPTsensitive 8402 cell line.

Each of the STR TOP1 cleavage substrates were synthesized as single-stranded oligonucleotides (DNA technology, Aarhus, Denmark).

I) D7S820 locus (8 repeats of GATA): 50-base top strand (5'$>3^{\prime}$ ): ACGTCACGGGATAGATAGATAGATAGATAGATAGAT AGATACGGTTCAGC; 50-base bottom strand (5'->3'): GCTGAACCGTATCTATCTATCTATCTATCTATCTATCTATC CCGTGACGT.

II) D5S818 locus (12 repeats of AGAT): 60-base top strand (5'$>3$ '): ACGTCACGGAGATAGATAGATAGATAGATAGATAGAT AGATAGATAGATAGATAGATCGGTTCAGC; 60-base bottom strand $\left(5^{\prime}->3^{\prime}\right)$ : GCTGAACCGATCTATCTATCTATCTATCTAT CTATCTATCTATCTATCTATCTATCTCCGTGACGT.

III) Thyroid peroxidase (TPOX) locus (8 repeats of AATG): 50base top strand $\left(5^{\prime}->3^{\prime}\right)$ : ACGTCACGGAATGAATGAAT GAATGAATGAATGAATGAATGCGGTTCAGC; 50-base bottom strand $\left(5^{\prime}->3\right.$ '): GCTGAACCGCATTCATTCATTCATTCATT CATT CATTCATTCCGTGACGT.

To prepare the STR substrates for TOP1 cleavage reaction, 50 pmol of each top strand was separately hot-labeled with gammaATP essentially as described before (33). The reaction was stopped by ethanol precipitation using $\mathrm{NaCl}$ and after $80 \% \mathrm{EtOH}$ wash, and drying of the pellet, it was resuspended in $10 \mu \mathrm{l} 1 \mathrm{x}$ TOP1-cleavage buffer ( $5 \mathrm{mM} \mathrm{MgCl}_{2}, 5 \mathrm{mM} \mathrm{CaCl}_{2}$, and $10 \mathrm{mM}$ Tris-HCl, $\mathrm{pH} 7.5$ ). Then 50 pmol of the corresponding bottom strand was added, the mixture was left at $90^{\circ} \mathrm{C}$ for $2 \mathrm{~min}$ and allowed to anneal with the respective top strand by slowly cooling down to room temperature.

TOP1 STR cleavage reactions and detection. The TOP1 cleavage reaction was performed as described (33). Briefly, approximately 200 copies of the annealed oligonucleotides were used for cleavage reaction with 300 units of human TOP1 in the presence of $10 \mu \mathrm{M}$ CPT or dimethylsulfoxide, which was used as a solvent for CPT. The reaction was carried out at $37^{\circ} \mathrm{C}$ for $30 \mathrm{~min}$. and stopped by the addition of $0.2 \%$ SDS followed by $\mathrm{EtOH}$ precipitation. After precipitation and $80 \% \mathrm{EtOH}$ washing and drying of the pellet, it was resuspended in $10 \mu \mathrm{l}$ trypsin mix and incubated at $37^{\circ} \mathrm{C}$ for $30 \mathrm{~min}$ as described previously (33). Then $10 \mu \mathrm{l}$ of $2 \mathrm{x}$ Seq-buffer $(100 \%$ formamide, 1 mM EDTA, pH 8.0, 0.1\% bromophenol blue (BPB), and $0.1 \%$ xylene cyanol) (Sigma-Aldrich, Brøndby, Denmark) was added to each reaction. Approximately 16 counts per second was added to each lane of a $14 \%$ denaturating polyacrylamide gel and run until BPB left the gel. The gel was transferred to Whatman
Table I. Immunophenotype of RPMI-8402 and CPT-K5

\begin{tabular}{lccc}
\hline Antigen & $\begin{array}{c}\text { RPMI-8402 } \\
\text { (DMSZ) }\end{array}$ & RPMI-8402 & CPT-K5 \\
\hline CD2 & + & + & + \\
CD3 & - & - & - \\
CD4 & - & n.d. & n.d \\
CD5 & + & + & + \\
CD6 & + & n.d. & n.d. \\
CD7 & + & + & + \\
CD8 & - & - & - \\
CD13 & - & - & - \\
CD19 & - & - & - \\
CD33 & n.i. & + & - \\
CD34 & + & + & - \\
CD45 & n.i. & + & + \\
CD71 & n.i. & - & + \\
CD235a & n.i. & n.d. & n.d. \\
TCR- $\alpha / \beta$ & - & n.d. & n.d. \\
TCR- $\gamma / \delta$ & - & & \\
\hline
\end{tabular}

aInformation from DMSZ web-site, http://www.dsmz.de; bn.i., no information; ${ }^{\mathrm{n}}$.d., not done.

3MM filter paper (Sigma-Aldrich Chemie $\mathrm{GmbH}$ ), dried and exposed in a phosphor imager (PMI Imager; Bio-Rad, Life Science, Bio-RAD laboratories, Copenhagen, Denmark).

\section{Results and Discussion}

Cellular characteristics of CPT-K5 and its CPT-resistant $C P T-K 5$ cell line. To obtain a global genomic insight into the development of acquired CPT resistance and to identify putative candidate genes involved in this process, we took advantage of the CPT-K5 cell line, which exhibits highly stable CPT resistance following prolonged CPT-selective growth of its parental RPMI-8402 cell line $(11,24,34)$.

For the purposes of the present study, we wanted to confirm the cellular and biochemical characteristics of these cell lines using current methods. Firstly, immunophenotyping of the parental cell line RPMI-8402 confirmed that it is indeed a T-ALL derived cell line (Table I). The CPT-K5 cell line has not previously been characterized by immunophenotyping but this analysis confirmed that CPT$\mathrm{K} 5$ retains the predominant T-ALL immunophenotype (Table I). Secondly, at the genetic level it was confirmed that the RPMI-8402 harbors two T-ALL specific chromosomal aberrations: i) the common $S I L$ deletion at chromosome region 1p32; and ii) the rare $\mathrm{t}(11 ; 14)(\mathrm{p} 15 ; \mathrm{q} 11) / L M O 1-T C R D$. Both aberrations were present in two copies (Figure 1). CPT$\mathrm{K} 5$ has retained one of the chromosome 1 that harbors the 1 p32 deletion, while the $t(11 ; 14)$ was completely lost (Figure 1). Thirdly, in a standard cell survival assay the CPT-resistant and the CPT-sensitive phenotypes of the CPT-K5 and RPMI- 


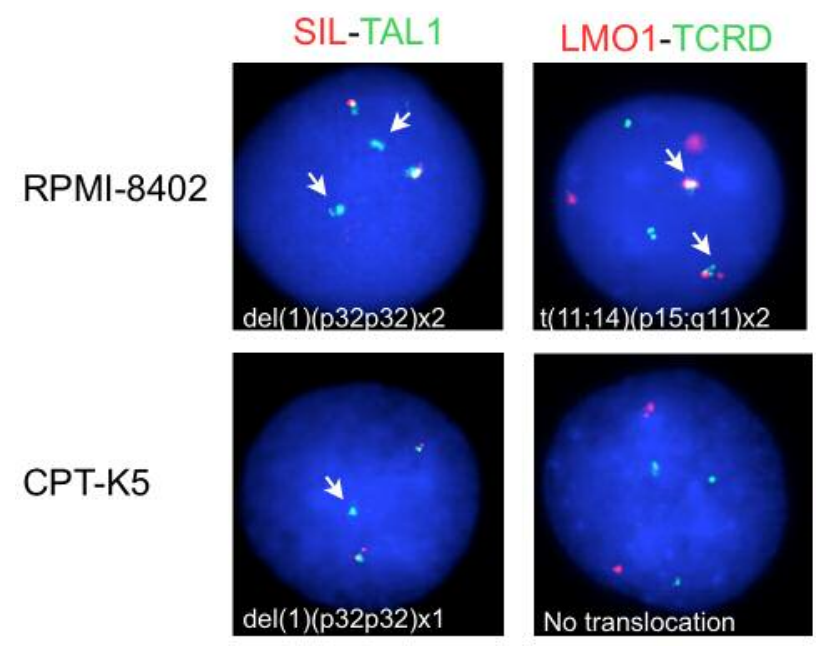

Figure 1. Fluorescence in situ hybridization (FISH) analysis of RPMI8402 cell line using the SIL-TAL1 split-apart probe set showing a nucleus with $2 F 2 G$ pattern indicating deletion of the SCL/TAL1Interrupring locus (STIL) gene in two alleles and a normal fusion in the other two alleles. FISH analysis using of RPMI-8402 cell line using the LMO1-TCRD single fusion probe showing a nucleus with $2 F 2 R 2 G$ pattern indicating fusion of the LIM domain only 1 (LMO1) and the Tcrd T cell receptor delta chain (TCRD) genes in two alleles and no fusion in the other two alleles. FISH analysis of CPT-K5 cell line using the TAL1-STIL split-apart probe showing a nucleus with $2 F 1 G$ pattern indicating deletion of the STIL gene in one allele and a normal fusion in the other two alleles. FISH analysis using of CPT-K5 cell line using the LMO1-TCRD single fusion probe showing a nucleus with $3 R 3 G$ pattern indicating no fusion of the genes.

8402 cell lines, respectively, were confirmed. As demonstrated in Figure 2A, cell proliferation was significantly reduced in the presence of $1 \mu \mathrm{M}$ CPT in the CPT-sensitive parental cell line RPMI-8402, while the CPTresistant derivative cell line, CPT-K5, did not exhibit any significant change in growth rate. In the absence of CPT, the cellular growth rate of the CPT-K5 was lower as compared to its parental cell line, which seems to be a common feature of CPT-resistant cell lines (22). Fourthly, we compared the TOP1 activity expressed in the two cell lines by western blotting and REEAD assay $(35,36)$. In line with previous studies, we found a reduced intra-cellular level of TOP1 protein in CPT-K5 cells relative to RPMI-8402 cells (Figure 2B). The cellular TOP1 activity was measured using the REEAD assay, which allows quantification of TOP1 cleavage-ligation activity in crude extracts from only a few human cells (schematically illustrated in Figure 2C) $(35,36)$. With the REEAD assay, we found a 2- to 3-fold reduction in cellular TOP1 enzymatic activity (Figure 2D). Moreover, the previously observed CPT-resistant phenotype of purified TOP1 expressed in CPT-K5 cells $(11,24)$ was confirmed by measuring the effect of CPT on TOP1 activity present in crude extracts from the CPT-K5 and its parental cell lines using the REEAD assay (Figure 2E).

Taken together, our present findings are in agreement with previous studies by Andoh et al. (11) and Kjeldsen et al . (24), and establish that the CPT-K5 cell line is a T-ALL derived cell line with unique characteristics.

Chromosomal analysis of CPT-K5 and RPMI-8402 cells. The CPT-K5 cell line has not previously been characterized by karyotyping, whereas its parental cell line RPMI-8402 had a partial or incomplete karyotype available as described elsewhere (37-40) and by DSMZ (Braunschweig, Germany; http://www.dsmz.de). In agreement with these earlier reports, we found that the RPMI-8402 cell line is hypo-tetraploid with a modal chromosomal number of 90 (range=76-92) (Figure $3 \mathrm{~A}$ and $\mathrm{B}$; Table II). In the present study, we completed the karyotype by defining the three previously assigned marker chromosomes to be: $\operatorname{del}(\mathrm{X})(\mathrm{q} 13.2 \mathrm{q} 22.1)$, $\operatorname{del}(2)(\mathrm{q} 11.2 \mathrm{q} 23.7)$ and $\operatorname{der}(15) \mathrm{t}(14 ; 15)(\mathrm{q} 32.2 ; \mathrm{p} 11)$.

The karyotype of the CPT-K5 cell line is also hypotetraploid but with a modal chromosome number of 80 (range=71-81) (Figure 3C and D; Table II). The most prominent differences between CPT-K5 and its parental RPMI8402 are: i) a reduced modal chromosomal number from 90 to 80; ii) loss of five structurally aberrant chromosomes: $\operatorname{del}(\mathrm{Xq})$, $\operatorname{del}(2 q)$, dup (4q), del( $6 q)$, and $t(11 ; 14)$; and iii) gain of 13 new structurally aberrant chromosomes: $\operatorname{der}(1) \mathrm{t}(1 ; 10)$, der(2) $\mathbf{t}(2 ; 6)$, $\operatorname{der}(4) \mathbf{t}(4 ; 17), \quad \operatorname{der}(6) \mathbf{t}(6 ; 16), \quad \operatorname{der}(7) \mathbf{t}(7 ; 8), \quad \operatorname{der}(8) \mathbf{t}(8 ; 9)$, $\operatorname{der}(9) \mathrm{t}(4 ; 9), \operatorname{der}(10) \mathrm{t}(10 ; 20), \operatorname{der}(12) \mathrm{t}(4 ; 12), \operatorname{der}(16) \mathrm{t}(3 ; 16)$, $\operatorname{der}(19) \mathrm{t}(3 ; 19)$, der(20)t(9;20), and $\operatorname{der}(22) \mathrm{t}(3 ; 22 ; 3)$. Despite these major karyotypic differences between the two cell lines affecting almost all chromosomes, chromosomes 5, 18, and 21 were cytogenetically unaffected.

Although several human cell lines resistant to CPT or its derivatives have been developed (Table III) only the CPT$\mathrm{K} 5$ cell line has so far been studied by karyotyping analysis as described above. This is intriguing from a biological point of view since TOP1 exerts its main activity in DNA metabolism by cleavage and rejoining, and that the latter is inhibited by CPT causing DNA strand breaks, which ultimately may induce chromosomal aberrations and genomic instability $(23,41)$. Spectral karyotyping of the doxorubicin-resistant cell line, NCI-H69AR, which is crossresistant to several topoisomerase II inhibitors, revealed substantial structural chromosomal differences compared with its parental NCI-H69 cell line (42). Similar chromosomal findings were obtained for mitoxantroneresistant SF295 cells (43). Together these data suggest that acquisition of resistance to drugs inhibiting DNA cleavagerejoining/metabolizing topoisomerases is accompanied by major karyotypic alterations, although the molecular mechanisms behind such alterations remain obscure. 
A
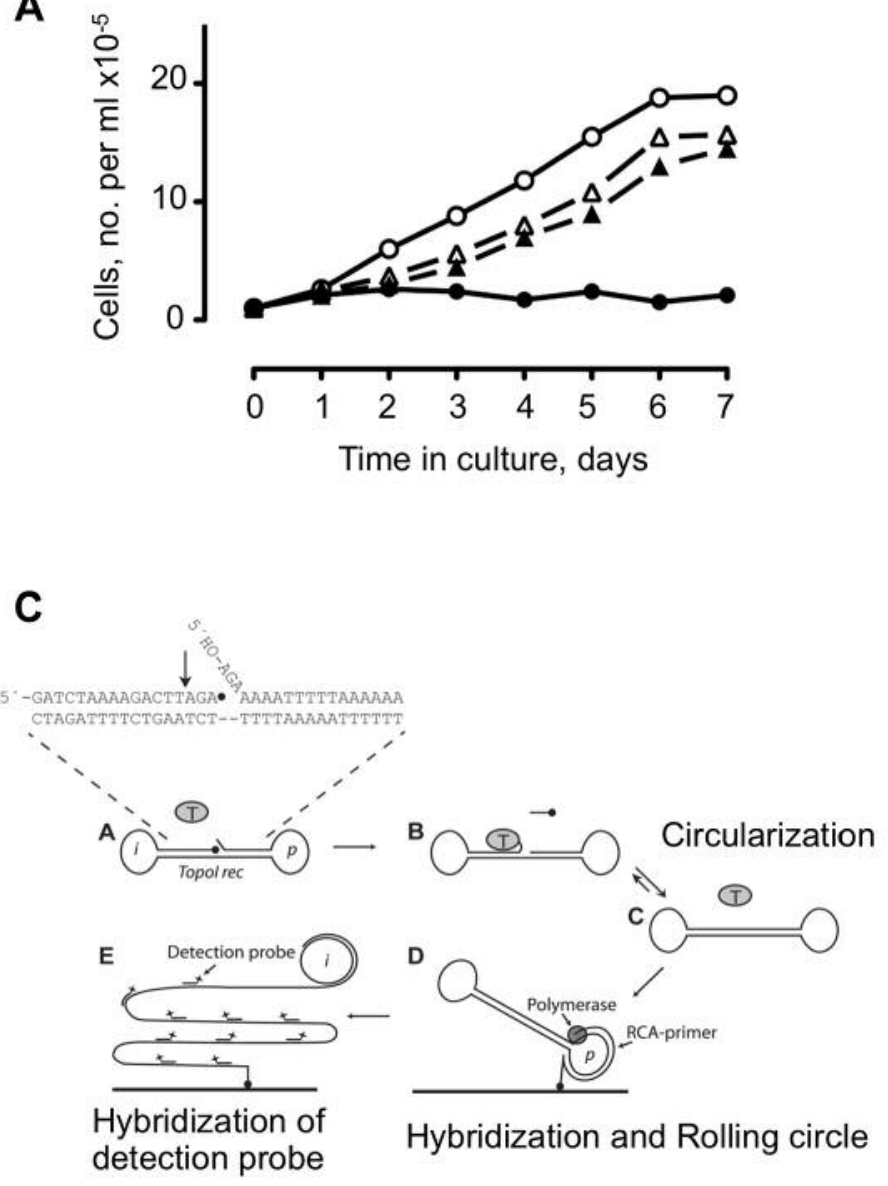

B

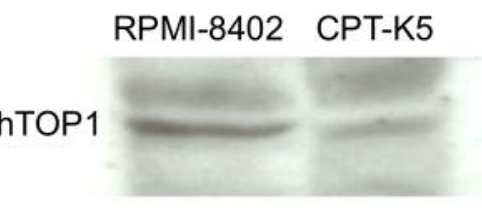

D

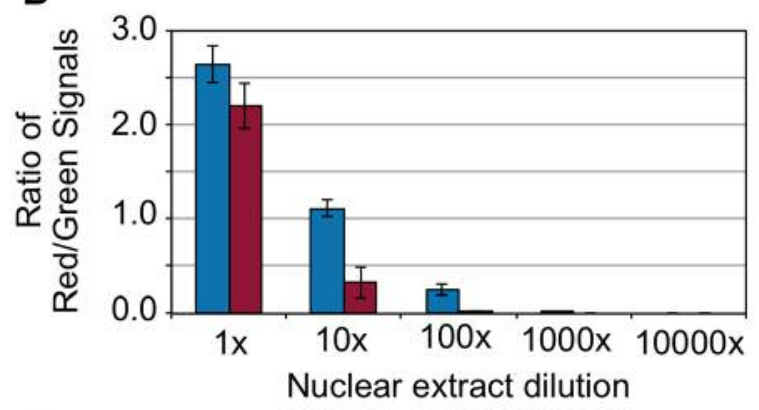

E

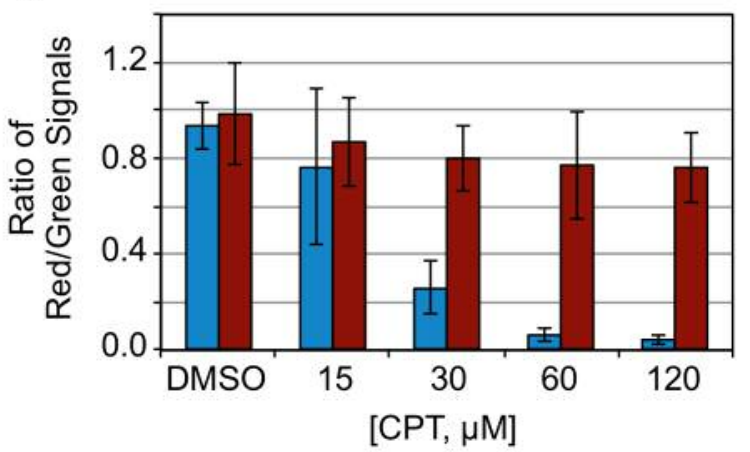

Figure 2. A: Effects of camptothecin (CPT) on cell growth of parental RPMI-8402 and CPT-K5 cells. Growth of parental cells in the absence (O) and presence of $1 \mu M C P T(\mathbf{\bullet})$. Growth of $C P T-K 5$ in the absence $(\triangle)$ and presence of $1 \mu M C P T(\mathbf{\Delta})$. B: Western blot of nuclear extracts from $10^{6}$ cells of RPMI-8402 and CPT-K5 using mouse antibody against human topoisomerase 1 (hTOP1). C: Schematic representation of the rollingcircle enhanced enzyme activity detection (REEAD) assay. A dumbbell-shaped DNA substrate with a preferred TOP1 cleavage sequence in the double-stranded stem region and an identifier- or primer annealing sequence (denoted " $i$ " or " $p$ ") in each of the loops is converted to a closed circle upon cleavage and ligation by TOP1. The generated circle is then hybridized to a surface anchored primer with a sequence matching the " $p$ " region and subjected to rolling circle amplification by added phi-polymerase. The resulting tandem repeat rolling circle product is visualized at the single molecule level by hybridization of fluorescent labeled detection probes matching the " $i$ " region. D: REEAD measurement of hTOP1 in nuclear extracts generated from 106 cells and assayed either undiluted (1x) or 10, 100, 1000, or 10,000 times diluted as indicated. E: The CPT sensitivity of hTOP1 in extracts from RPMI-8402 (blue bars) and CPT-K5 (red bars) was analyzed by measuring the activity using the REEAD assay in the presence of increasing concentrations of CPT as indicated. The bar chart shows the mean values from three independent experiments and the error bars indicate standard deviations.

Genomic profiling reveals greatly increased number of genomic DNA breakpoints in CPT-K5 cells. To further characterize the observed chromosomal differences between RPMI-8402 and CPT-K5 cells, we examined copy number changes between the cell lines by oligo-based aCGH analysis using female DNA pooled from normal individuals as reference (Figure 4A). For RPMI-8402 cells, the observed copy number aberrations were in agreement with the published SNP Array Based LOH and Copy Number
Analysis (Welcome Sanger Trust Institute, http:// www.sanger.ac.uk/cgi-bin/genetics/CGP/cghviewer). The oligo-based aCGH analysis of CPT-K5 cells confirmed the major differences as revealed by karyotyping (Figure 4B).

For a detailed comparison, however, the approach of comparing oaCGH analyses with DNA from normal individuals serving as a reference is imprecise. Subtractive $\mathrm{CGH}$ analysis is a direct method for determining genomic changes between drug-resistant cell lines where DNA from 
A. RPMI-8402, G-banding

\begin{tabular}{|c|c|c|c|c|c|c|}
\hline get & of & if & है & \multicolumn{2}{|c|}{ 188 } & \\
\hline 1 & 2 & 3 & 4 & 5 & & mar \\
\hline औิ & 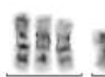 & 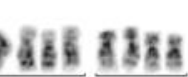 & 348 & 358 & हैं \&: & 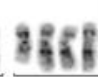 \\
\hline 6 & 7 & 8 & 10 & 11 & 12 & $x$ \\
\hline 68 & $g * \cdots$ & 434 & tis & $38: 5$ & BEZ & \\
\hline 13 & 14 & 15 & 16 & 17 & 18 & \\
\hline $3 \times 8$. & 89884 & $\ldots$ & $m$ & & & \\
\hline 19 & 20 & 21 & 22 & & $Y$ & \\
\hline
\end{tabular}

B. RPMI-8402, Spectral karyotyping

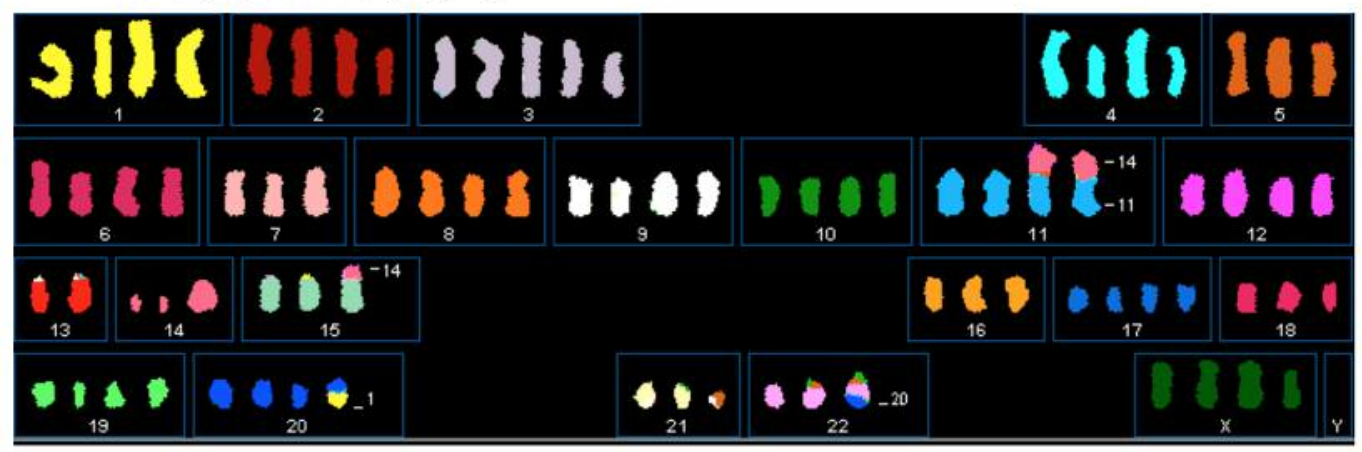

C. CPT-K5, G-banding

\begin{tabular}{|c|c|c|c|c|c|c|c|}
\hline 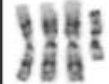 & 3 & 8 & & สิt & 2 & & $t$ \\
\hline 1 & $\frac{7}{2}$ & 3 & & 4 & 5 & & mar \\
\hline 86 & 10. & Iำ & 1835 & 6 \& & $i \in 6$ & 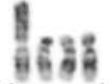 & 16 \\
\hline 6 & 7 & 8 & 9 & 10 & 11 & 12 & $x$ \\
\hline Blate & gts & 890 & & 2838 & Ka & है 56 & \\
\hline 13 & 14 & 15 & & 16 & 17 & 18 & \\
\hline 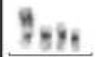 & 9888 & & 806 & goa & & & \\
\hline 19 & 20 & & 21 & 22 & & $Y$ & \\
\hline
\end{tabular}

D. CPT-K5, Spectral karyotyping

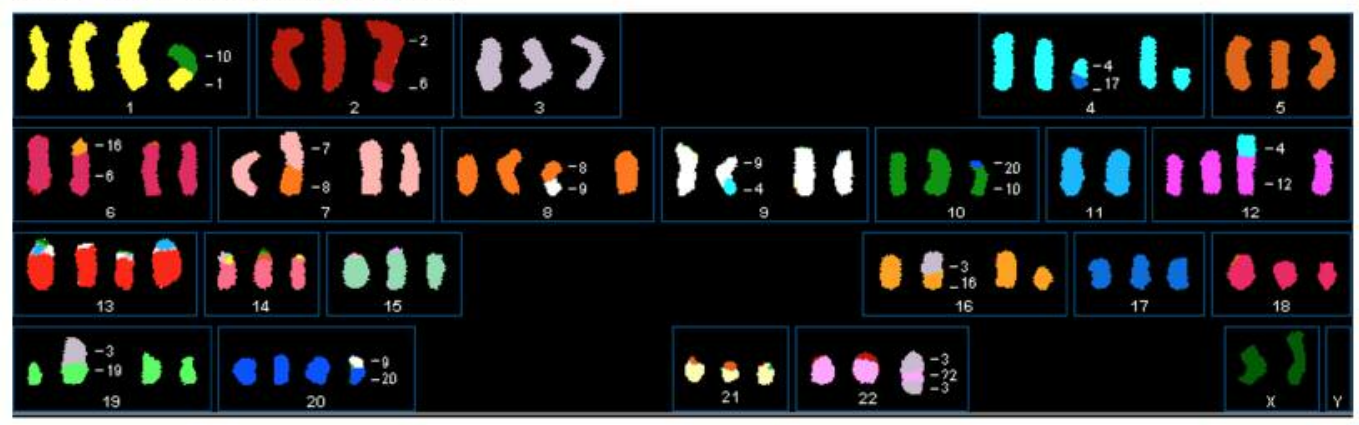

Figure 3. G-Banding $(A, C)$ and spectral karyotyping $(B, D)$ of the RPMI-8402 $(A, B)$ and CPT-K5 $(C, D)$ cell lines showing representative karyotypes. 
Table II. Karyotypes of the camptothecin (CPT)-resistant cell line CPT-K5 and its parental CPT-sensitive RPMI-8402 cell line.

\begin{tabular}{|c|c|}
\hline Cell line & Karyotype \\
\hline RPMI-8402 & $\begin{array}{c}90<4 \mathrm{n}>, \mathrm{XXX}, \operatorname{del}(\mathrm{X})(\mathrm{q} 13.2 \mathrm{q} 22.1), \operatorname{del}(2)(\mathrm{q} 11.2 \mathrm{q} 37.3),+3, \operatorname{dup}(4)(\mathrm{q} 13.1 \mathrm{q} 25) \times 2,-5, \operatorname{del}(6)(\mathrm{q} 13 \mathrm{q} 21) \times 2,-7, \mathrm{t}(11 ; 14) \\
(\mathrm{p} 15 ; \mathrm{q} 11) \times 2,-13,-13,-15, \operatorname{der}(15) \mathrm{t}(14 ; 15)(\mathrm{q} 32.2 ; \mathrm{p} 11),-16,-18, \operatorname{der}(20) \mathrm{t}(1 ; 20)(\mathrm{p} 36.1 ; \mathrm{q} 11.21), \operatorname{der}(22) \mathrm{t}(20 ; 22) \\
(\mathrm{q} 11.21 ; \mathrm{q} 13.33) \text { and a minor sideline with an additional } \operatorname{der}(1) \mathrm{t}(1 ; 8)(\mathrm{p} 3 ? 5 ; \mathrm{q} 11)\end{array}$ \\
\hline CPT-K5 & $\begin{array}{c}80<4 \mathrm{n}>, \mathrm{XX},-\mathrm{X},-\mathrm{X}, \operatorname{der}(1) \mathrm{t}(1 ; 10)(\mathrm{p} 10 ; \mathrm{q} 11) \operatorname{del}(1)(\mathrm{q} 25),-2, \mathrm{t}(2 ; 6)(\mathrm{q} 37:: \mathrm{p} 12.3 \mathrm{p} 11.2),-3,+4, \operatorname{der}(4) \mathrm{t}(4 ; 17)(\mathrm{q} ? 11 ; \mathrm{q} 25) \\
\operatorname{del}(4)(\mathrm{q} 11),-5, \operatorname{der}(6) \mathrm{t}(6 ; 16)(\mathrm{p} 21 ; \mathrm{q} 11), \operatorname{der}(7) \mathrm{t}(7 ; 8)(\mathrm{q} 36 ; \mathrm{q} 13), \operatorname{der}(8) \mathrm{t}(8 ; 9)(\mathrm{q} 12 ; \mathrm{q} 33), \mathrm{i}(9)(\mathrm{q} 10), \operatorname{der}(9) \mathrm{t}(4 ; 9) \\
\quad-10, \operatorname{der}(10) \mathrm{t}(10 ; 20)(\mathrm{p} 15 ; ?),-11,-11, \mathrm{t}(4 ; 12)(\mathrm{q} 22 \mathrm{q} 21:: \mathrm{p} 13),-14,-15, \operatorname{der}(16) \mathrm{t}(3 ; 16)(\mathrm{q} 21 ; \mathrm{q} 11),-17,-18 \\
\operatorname{der}(19) \mathrm{t}(3 ; 19)(\mathrm{p} 21 ; \mathrm{p} 13), \operatorname{der}(20) \mathrm{t}(9 ; 20),-21, \operatorname{der}(22) \mathrm{t}(3 ; 22 ; 3) \text { and a minor sideline with del(6)(q14q21) }\end{array}$ \\
\hline
\end{tabular}

Table III. Human cell lines developed after selection of resistance to camptothecin (CPT) or its derivatives.

\begin{tabular}{|c|c|c|c|c|c|c|}
\hline $\begin{array}{l}\text { Resistant } \\
\text { cell line }\end{array}$ & Parental & $\begin{array}{c}\text { Parental } \\
\text { cancer }\end{array}$ & $\begin{array}{l}\text { Selection } \\
\text { agent }\end{array}$ & $\begin{array}{l}\text { TOP1 point } \\
\text { mutation }\end{array}$ & $\begin{array}{c}\text { Karyotype } \\
\text { available (Ref) }\end{array}$ & Reference \\
\hline CPT-K5 & RPMI-8402 & T-ALL & CPT-11 & Asp533Gly & $\begin{array}{c}\text { P: Yes (see Table II) } \\
\text { R: Yes, present study (see Table II) }\end{array}$ & $(11,34)$ \\
\hline PC-7/CPT & PC-7 & Non-small cell lung cancer & CPT-11 & Thr729Ala & $\begin{array}{l}\text { P: No } \\
\text { R: No }\end{array}$ & $(12,13)$ \\
\hline A549/CPT & A549 & Lung cancer & $\mathrm{CPT}$ & None & $\begin{array}{c}\text { P: Yes, (97) } \\
\text { R: No, but CGH analysis (44) }\end{array}$ & (14) \\
\hline St-4/CPT & St-4 & Gastric cancer & $\mathrm{CPT}$ & $\begin{array}{l}\text { No, but ex3 } \\
\text { to ex9 deletion }\end{array}$ & $\begin{array}{c}\text { P: No } \\
\text { R: No, but CGH analysis (44) }\end{array}$ & (14) \\
\hline HT-29/CPT & HT-29 & Colon cancer & $\mathrm{CPT}$ & $\begin{array}{l}\text { No, but ex3 } \\
\text { to ex9 deletion }\end{array}$ & $\begin{array}{l}\text { P: No } \\
\text { R: No, but CGH analysis, (44) }\end{array}$ & (14) \\
\hline U937/CR & U937 & Myeloid leukemia & $9-\mathrm{NC}$ & Phe361Ser & $\begin{array}{l}\text { P: Yes (98) } \\
\text { R: No }\end{array}$ & (15) \\
\hline $\begin{array}{l}\mathrm{CEM} / \mathrm{C} 1 \text { and } \\
\mathrm{CEM} / \mathrm{C} 2\end{array}$ & CCRF-CEM & T-ALL & $\mathrm{CPT}^{*}$ & Asn722Ser & $\begin{array}{l}\text { P: Yes (99) } \\
\text { R: No }\end{array}$ & (16) \\
\hline $\begin{array}{l}\text { DU-145/RC0.1 } \\
\text { DU-145/RC1 }\end{array}$ & DU145 & Prostate cancer & $9-\mathrm{NC}$ & Arg364His & $\begin{array}{l}\text { P: Yes }(100,101) \\
\text { R: No }\end{array}$ & $(17,18)$ \\
\hline U937/RERC & U937 & Myeloid leukemia & $9-\mathrm{NC}$ & Asp533Asn & $\begin{array}{l}\text { P: Yes } \\
\text { R: No }\end{array}$ & (19) \\
\hline СРТ30 & HONE-1 & Nasopharyngeal carcinoma & $\mathrm{CPT}$ & Glu418Lys & $\begin{array}{l}\text { P: No } \\
\text { R: No }\end{array}$ & $(20)$ \\
\hline $\begin{array}{l}\text { MMRU/CR1 and } \\
\text { MMRU/CR2 }\end{array}$ & MMRU & Melanoma & CPT-11 & None & $\begin{array}{c}\text { P: No } \\
\text { R: No, but BAC-based } \\
\text { aCGH analysis }(21)\end{array}$ & $(21)$ \\
\hline $\begin{array}{l}\text { SF295/hCPT50 and } \\
\text { SF295/BN50 }\end{array}$ & SF295 & Glioblastoma & $\begin{array}{l}\text { hCPT and } \\
\text { BN80915 }\end{array}$ & None & $\begin{array}{l}\text { P: Yes (43) } \\
\text { R: No }\end{array}$ & $(55)$ \\
\hline $\begin{array}{l}\text { HT-29/SN-38 } \\
\text { HCT-116/SN-38 }\end{array}$ & $\begin{array}{c}\text { HT-29 } \\
\text { HCT-116 }\end{array}$ & $\begin{array}{l}\text { Colon cancer } \\
\text { Colon cancer }\end{array}$ & SN38 & $\begin{array}{c}\text { None } \\
\text { Arg364Lys } \\
\text { and Gly721Arg }\end{array}$ & $\begin{array}{l}\text { P: No } \\
\text { R: No }\end{array}$ & $(22)$ \\
\hline
\end{tabular}

P: Parental; R: resistant; T-ALL: T-cell lymphoblastic leukemia, 9-NC: 9-nitro-20(S)camptothecin; hCPT: homocamptothecin; BN80915: hCPT derivative; SN-38:7-ethyl-10-hydroxy-20(S)-camptothecin. *Resistance stable for up to 6 months.

the parental cell line serves as reference DNA $(44,45)$. The subtractive oligo-based aCGH analytical approach, where the RPMI-8402 DNA served as a reference, revealed that CPTK5 cells had acquired 165 copy number alterations (Figure 4C, Table IV).

Calculating the mere number of copy number alterations underestimates the number of putative DNA breakage points
(46). We assessed those DNA breakage points at the edges of segments of DNA copy number gains and losses, as well as at points of abrupt DNA copy number changes called within larger aberrations as exemplified in Figure 4D. By this analysis, we found that CPT-K5 cells had acquired a total of 236 unbalanced breakpoints that were unevenly distributed across each chromosome (Figure 4D). The 
A

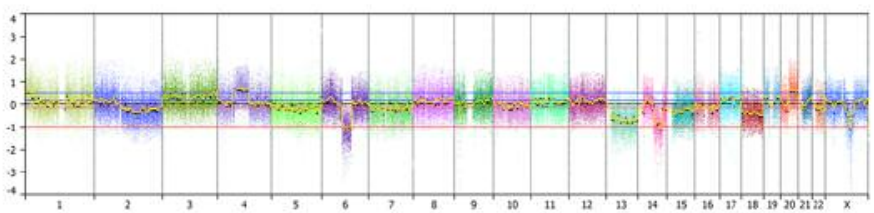

B

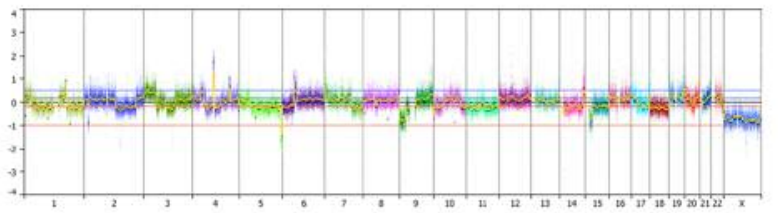

C
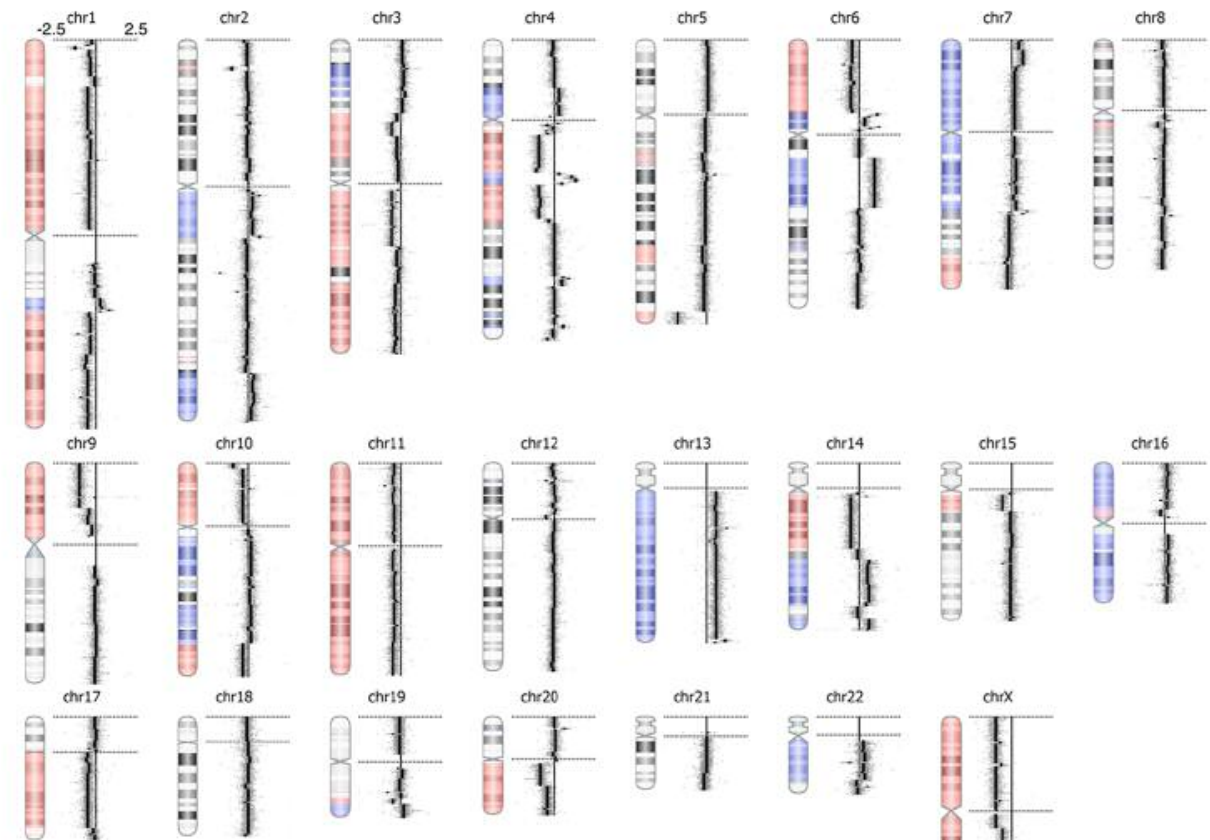

D
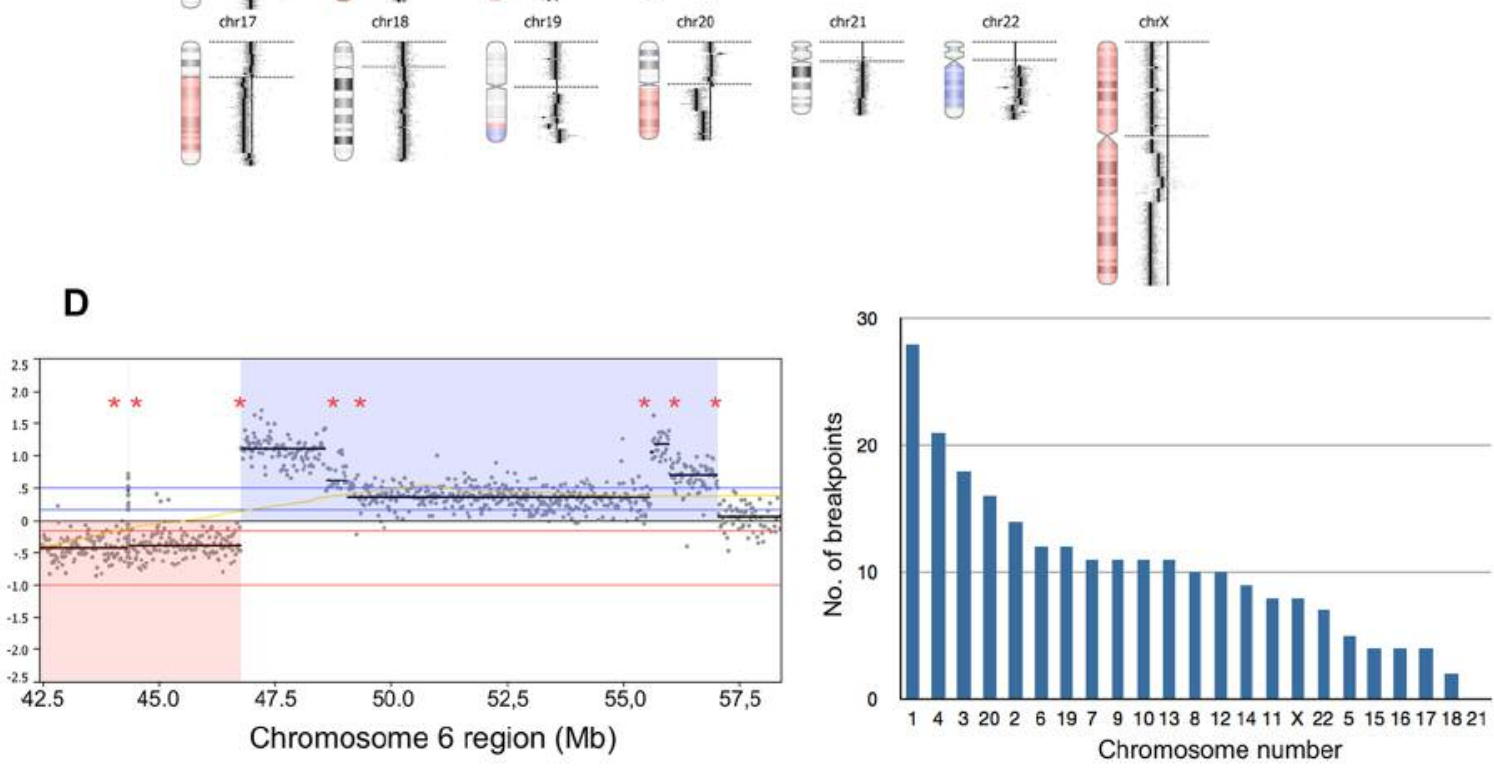

Figure 4. Genomic profiling using 180k oligo-based array comparative genomic hybridization (aCGH) analysis. A: Whole-genome view of RPMI8402 against normal female DNA pool. B: Whole-genome view of CPT-K5 against normal female DNA pool. C: Subtractive aCGH analysis where RPMI-8402 served as reference. To the right of the individual ideograms, microarray profiles of copy number gains and losses are depicted. Gain is indicated by blue and loss is indicated by red as an overlay on the ideogram. The log 2 ratios for each chromosome are $-2.5,0$, and +2.5 as illustrated for chromosome 1. D: Subtractive aCGH-based breakpoint analysis. Left panel: Magnified view of copy number profile of a region on chromosome 6 (pos. 42,500,000-58,000,000 bp) in which asterisks indicate determined putative DNA breakpoints. Focusing on the called regions of loss (red) and gain (blue) indicates two breakpoints, while taking copy number changes within the called regions into account, eight putative DNA break points can be determined. Right panel. Diagram showing the number of putative DNA break points determined on each chromosome. 
Kjeldsen et al: Camptothecin-induced Genomic Changes in CPT-K5 Cells

Table IV. Results from subtractive oligo array-based comparative genomic hybridization analysis between CPT-K5 and RPMI-8402 (hg18) cell lines.

\begin{tabular}{|c|c|c|c|c|}
\hline Chromosomal region & Copy number aberration & Length (bp) & Cytoband & No. of probes \\
\hline $\operatorname{chr} 1: 0-4,617,760$ & Loss & 4617761 & p36.33 - p36.32 & 347 \\
\hline $\operatorname{chr} 1: 4,617,760-6,731,626$ & Homozygous copy loss & 2113867 & p36.32- p36.31 & 135 \\
\hline $\operatorname{chr} 1: 6,731,626-23,383,050$ & Loss & 16651425 & p36.31-p36.12 & 1028 \\
\hline chr1:29,939,359-40,135,057 & Loss & 10195699 & p35.3 - p34.2 & 667 \\
\hline $\operatorname{chr} 1: 40,232,695-47,470,334$ & Loss & 7237640 & $\mathrm{p} 34.2-\mathrm{p} 33$ & 518 \\
\hline $\operatorname{chr} 1: 47,555,023-76,314,989$ & Loss & 28759967 & p33-p31.1 & 1702 \\
\hline $\operatorname{chr} 1: 76,687,243-121,052,423$ & Loss & 44365181 & p31.1 - p11.2 & 2547 \\
\hline chr1:147,259,828-148,058,607 & Loss & 798780 & $\mathrm{q} 21.1-\mathrm{q} 21.2$ & 30 \\
\hline $\operatorname{chr} 1: 164,645,796-171,310,019$ & Gain & 6664224 & $\mathrm{q} 24.1-\mathrm{q} 25.1$ & 417 \\
\hline $\operatorname{chr} 1: 171,310,019-172,363,398$ & High copy gain & 1053380 & $\mathrm{q} 25.1$ & 62 \\
\hline $\operatorname{chr} 1: 172,363,398-172,978,604$ & Gain & 615207 & $\mathrm{q} 25.1$ & 37 \\
\hline $\operatorname{chr} 1: 172,978,604-247,249,719$ & Loss & 74271116 & $\mathrm{q} 25.1-\mathrm{q} 44$ & 4372 \\
\hline $\operatorname{chr} 2: 82,105-2,351,466$ & Loss & 2269362 & p 25.3 & 139 \\
\hline chr2:17,082,892-19,555,672 & Loss & 2472781 & $\mathrm{p} 24.2-\mathrm{p} 24.1$ & 129 \\
\hline chr2:47,871,668-47,913,372 & Loss & 41705 & $\mathrm{p} 16.3$ & 26 \\
\hline chr2:96,685,923-98,987,015 & Gain & 2301093 & $\mathrm{q} 11.2$ & 122 \\
\hline chr2:98,987,015-99,310,234 & High copy gain & 323220 & $\mathrm{q} 11.2$ & 21 \\
\hline $\operatorname{chr} 2: 99,310,234-115,209,148$ & Gain & 15898915 & $\mathrm{q} 11.2-\mathrm{q} 14.1$ & 891 \\
\hline chr2:115,209,148-115,389,211 & High copy gain & 180064 & $\mathrm{q} 14.1$ & 11 \\
\hline chr2:115,389,211-124,331,966 & Gain & 8942756 & $\mathrm{q} 14.1-\mathrm{q} 14.3$ & 473 \\
\hline chr2:124,331,966-125,952,676 & High copy gain & 1620711 & $\mathrm{q} 14.3$ & 89 \\
\hline chr2:147,977,155-148,340,965 & Homozygous copy loss & 363811 & $\mathrm{q} 22.3$ & 16 \\
\hline chr2:160,098,019-160,395,597 & Loss & 297579 & $\mathrm{q} 24.2$ & 19 \\
\hline chr2:200,685,674-201,878,147 & Loss & 1192474 & $\mathrm{q} 33.1$ & 102 \\
\hline $\operatorname{chr} 2: 211,746,930-232,604,377$ & Gain & 20857448 & $\mathrm{q} 34-\mathrm{q} 37.1$ & 1322 \\
\hline $\operatorname{chr} 2: 232,604,377-232,810,269$ & High copy gain & 205893 & $\mathrm{q} 37.1$ & 13 \\
\hline $\operatorname{chr} 2: 232,810,269-242,118,949$ & Gain & 9308681 & $\mathrm{q} 37.1-\mathrm{q} 37.3$ & 591 \\
\hline $\operatorname{chr} 3: 4,499,856-4,714,317$ & Loss & 214462 & $\mathrm{p} 26.2$ & 13 \\
\hline chr3:15,760,147-30,673,114 & Gain & 14912968 & $\mathrm{p} 24.3-\mathrm{p} 24.1$ & 847 \\
\hline chr3:32,894,032-36,997,480 & Gain & 4103449 & $\mathrm{p} 22.3-\mathrm{p} 22.2$ & 218 \\
\hline $\operatorname{chr} 3: 46,704,902-75,717,747$ & Loss & 29012846 & $\mathrm{p} 21.31-\mathrm{p} 12.3$ & 1868 \\
\hline $\operatorname{chr} 3: 96,119,738-131,498,439$ & Loss & 35378702 & $\mathrm{q} 11.2-\mathrm{q} 21.3$ & 2074 \\
\hline chr3:133,661,863-144,156,885 & Loss & 10495023 & $\mathrm{q} 22.1-\mathrm{q} 23$ & 698 \\
\hline chr3:154,366,004-199,501,827 & Loss & 45135824 & $\mathrm{q} 25.2-\mathrm{q} 29$ & 2836 \\
\hline chr4:30,928,350-48,818,171 & Gain & 17889822 & $\mathrm{p} 15.1-\mathrm{p} 11$ & 1029 \\
\hline chr4:48,818,171-49,324,512 & Loss & 506342 & $\mathrm{p} 11$ & 13 \\
\hline chr4:52,379,976-54,001,926 & Gain & 1621951 & $\mathrm{q} 11-\mathrm{q} 12$ & 115 \\
\hline chr4:54,001,926-55,601,951 & Loss & 1600026 & q12 & 141 \\
\hline chr4:57,756,781-58,477,891 & Loss & 721111 & $\mathrm{q} 12$ & 36 \\
\hline chr4:59,282,223-84,667,611 & Loss & 25385389 & $\mathrm{q} 13.1-\mathrm{q} 21.23$ & 1379 \\
\hline chr4:84,667,611-86,334,752 & Gain & 1667142 & $\mathrm{q} 21.23$ & 91 \\
\hline chr4:86,334,752-90,572,723 & High copy gain & 4237972 & $\mathrm{q} 21.23-\mathrm{q} 22.1$ & 291 \\
\hline chr4:90,572,723-92,216,636 & Gain & 1643914 & $\mathrm{q} 22.1$ & 94 \\
\hline chr4:92,216,636-116,617,534 & Loss & 24400899 & $\mathrm{q} 22.1-\mathrm{q} 26$ & 1401 \\
\hline chr4:150,282,711-156,335,243 & High copy gain & 6052533 & $\mathrm{q} 31.23-\mathrm{q} 32.1$ & 408 \\
\hline chr4:174,686,909-176,738,183 & Gain & 2051275 & $\mathrm{q} 34.1-\mathrm{q} 34.2$ & 107 \\
\hline chr4: $180,929,325-183,265,266$ & High copy gain & 2335942 & $\mathrm{q} 34.3-\mathrm{q} 35.1$ & 115 \\
\hline chr4:189,587,206-191,040,830 & Loss & 1453625 & $\mathrm{q} 35.2$ & 84 \\
\hline chr5:72,172,204-76,597,348 & Loss & 4425145 & $\mathrm{q} 13.2-\mathrm{q} 14.1$ & 254 \\
\hline chr5:85,672,364-86,090,775 & High copy gain & 418412 & $\mathrm{q} 14.3$ & 22 \\
\hline chr5:130,374,979-142,235,475 & Loss & 11860497 & $\mathrm{q} 23.3-\mathrm{q} 31.3$ & 763 \\
\hline chr5:172,636,434-180,857,866 & Homozygous copy loss & 8221433 & $\mathrm{q} 35.2-\mathrm{q} 35.3$ & 452 \\
\hline chr6:0-44,324,035 & Loss & 44324036 & $\mathrm{p} 25.3-\mathrm{p} 21.1$ & 2863 \\
\hline chr6:44,324,035-44,330,142 & Gain & 6108 & $\mathrm{p} 21.1$ & 17 \\
\hline chr6:44,330,142-46,756,760 & Loss & 2426619 & $\mathrm{p} 21.1-\mathrm{p} 12.3$ & 147 \\
\hline chr6:46,756,760-49,038,560 & High copy gain & 2281801 & p 12.3 & 127 \\
\hline chr6:49,038,560-55,583,943 & Gain & 6545384 & $\mathrm{p} 12.3-\mathrm{p} 12.1$ & 369 \\
\hline
\end{tabular}

Table IV. Continued 
Table IV. Continued

\begin{tabular}{|c|c|c|c|c|}
\hline Chromosomal region & Copy number aberration & Length (bp) & Cytoband & No. of probes \\
\hline chr6:55,583,943-57,048,799 & High copy gain & 1464857 & p12.1 & 91 \\
\hline chr6:58,733,711-58,827,870 & Loss & 94160 & p11.1 & 5 \\
\hline chr6:74,906,801-107,152,528 & High copy gain & 32245728 & $\mathrm{q} 13-\mathrm{q} 21$ & 1733 \\
\hline chr6:130,196,488-133,067,603 & Gain & 2871116 & $\mathrm{q} 22.33-\mathrm{q} 23.2$ & 153 \\
\hline chr6:135,489,105-135,956,121 & Loss & 467017 & $\mathrm{q} 23.3$ & 44 \\
\hline chr6:137,243,750-137,499,193 & Gain & 255444 & $\mathrm{q} 23.3$ & 15 \\
\hline $\operatorname{chr} 7: 0-1,121,607$ & High copy gain & 1121608 & $\mathrm{p} 22.3$ & 53 \\
\hline $\operatorname{chr} 7: 1,121,607-7,035,288$ & Gain & 5913682 & $\mathrm{p} 22.3-\mathrm{p} 22.1$ & 446 \\
\hline chr7:7,035,288-16,220,801 & High copy gain & 9185514 & $\mathrm{p} 22.1-\mathrm{p} 21.1$ & 531 \\
\hline chr7:16,220,801-17,144,093 & Gain & 923293 & $\mathrm{p} 21.1$ & 53 \\
\hline chr7:17,144,093-17,274,506 & High copy gain & 130414 & $\mathrm{p} 21.1$ & 7 \\
\hline chr7:17,274,506-57,931,426 & Gain & 40656921 & $\mathrm{p} 21.1-\mathrm{p} 11.1$ & 2454 \\
\hline chr7:61,060,634-73,060,264 & Gain & 11999631 & $\mathrm{q} 11.1-\mathrm{q} 11.23$ & 641 \\
\hline chr7:75,463,022-91,853,628 & Gain & 16390607 & $\mathrm{q} 11.23-\mathrm{q} 21.2$ & 1061 \\
\hline chr7:92,385,908-98,849,814 & Gain & 6463907 & $\mathrm{q} 21.2-\mathrm{q} 22.1$ & 392 \\
\hline chr7:102,194,682-108,995,676 & Gain & 6800995 & $\mathrm{q} 22.1-\mathrm{q} 31.1$ & 404 \\
\hline $\operatorname{chr} 7: 108,995,676-109,629,306$ & High copy gain & 633631 & $\mathrm{q} 31.1$ & 38 \\
\hline chr7:110,609,962-111,191,239 & High copy gain & 581278 & $\mathrm{q} 31.1$ & 34 \\
\hline chr7:138,278,951-140,733,077 & Loss & 2454127 & q34 & 155 \\
\hline $\operatorname{chr} 7: 141,028,260-141,716,184$ & Loss & 687925 & $\mathrm{q} 34$ & 43 \\
\hline $\operatorname{chr} 7: 141,716,184-142,001,388$ & Homozygous copy loss & 285205 & $\mathrm{q} 34$ & 34 \\
\hline $\operatorname{chr} 7: 142,001,388-158,821,424$ & Loss & 16820037 & $\mathrm{q} 34-\mathrm{q} 36.3$ & 1033 \\
\hline chr8:6,939,167-8,140,313 & Loss & 1201147 & $\mathrm{p} 23.1$ & 42 \\
\hline chr8:51,018,695-51,876,043 & Gain & 857349 & $\mathrm{q} 11.22$ & 50 \\
\hline chr8:52,319,845-56,579,297 & Loss & 4259453 & $\mathrm{q} 11.22-\mathrm{q} 12.1$ & 313 \\
\hline chr8:75,594,717-75,816,663 & Loss & 221947 & $\mathrm{q} 21.11$ & 13 \\
\hline chr8:100,169,590-100,592,848 & Loss & 423259 & $\mathrm{q} 22.2$ & 26 \\
\hline chr8:111,840,142-112,654,585 & Gain & 814444 & $\mathrm{q} 23.2-\mathrm{q} 23.3$ & 39 \\
\hline chr9:0-21,791,953 & Loss & 21791954 & $\mathrm{p} 24.3-\mathrm{p} 21.3$ & 1323 \\
\hline chr9:22,331,315-47,059,042 & Loss & 24727728 & p21.3-p11.1 & 1193 \\
\hline chr9:101,646,358-102,093,247 & Loss & 446890 & $\mathrm{q} 31.1$ & 35 \\
\hline chr9:133,061,462-133,365,057 & High copy gain & 303596 & $\mathrm{q} 34.13$ & 36 \\
\hline $\operatorname{chr} 10: 0-15,888,483$ & Loss & 15888484 & p15.3- p13 & 952 \\
\hline $\operatorname{chr} 10: 16,915,490-36,318,413$ & Loss & 19402924 & $\mathrm{p} 13-\mathrm{p} 11.21$ & 1177 \\
\hline $\operatorname{chr} 10: 36,593,683-37,866,631$ & Loss & 1272949 & p11.21 & 64 \\
\hline chr10:41,927,663-42,119,299 & Gain & 191637 & $\mathrm{q} 11.1-\mathrm{q} 11.21$ & 9 \\
\hline chr10:46,207,943-48,328,997 & Gain & 2121055 & $\mathrm{q} 11.22$ & 81 \\
\hline chr10:49,279,264-51,016,781 & Gain & 1737518 & $\mathrm{q} 11.22-\mathrm{q} 11.23$ & 95 \\
\hline chr10:51,592,423-71,893,858 & Gain & 20301436 & $\mathrm{q} 11.23-\mathrm{q} 22.1$ & 1183 \\
\hline $\operatorname{chr} 10: 77,740,437-79,305,369$ & Gain & 1564933 & $\mathrm{q} 22.3$ & 91 \\
\hline chr10:89,615,986-89,851,240 & Loss & 235255 & $\mathrm{q} 23.31$ & 25 \\
\hline $\operatorname{chr} 10: 89,851,240-104,145,580$ & Gain & 14294341 & $\mathrm{q} 23.31-\mathrm{q} 24.32$ & 889 \\
\hline chr10:106,426,059-114,163,946 & Gain & 7737888 & $\mathrm{q} 25.1-\mathrm{q} 25.2$ & 445 \\
\hline $\operatorname{chr} 10: 114,163,946-124,316,045$ & Loss & 10152100 & $\mathrm{q} 25.2-\mathrm{q} 26.13$ & 598 \\
\hline chr10:124,382,777-135,374,737 & Loss & 10991961 & $\mathrm{q} 26.13-\mathrm{q} 26.3$ & 652 \\
\hline $\operatorname{chr11:0-3,759,910}$ & Loss & 3759911 & p15.5 - p15.4 & 395 \\
\hline $\operatorname{chr} 11: 3,759,910-4,116,151$ & Homozygous copy loss & 356242 & p 15.4 & 25 \\
\hline $\operatorname{chr11:4,116,151-51,407,929}$ & Loss & 47291779 & $\mathrm{p} 15.4-\mathrm{p} 11.11$ & 2735 \\
\hline $\operatorname{chr11:54,691,084-56,019,679}$ & Loss & 1328596 & q11 & 79 \\
\hline $\operatorname{chr} 11: 56,348,485-111,109,293$ & Loss & 54760809 & $\mathrm{q} 11-\mathrm{q} 23.1$ & 3569 \\
\hline chr11:111,109,293-111,379,863 & Gain & 270571 & $\mathrm{q} 23.1$ & 15 \\
\hline $\operatorname{chr} 11: 111,379,863-134,452,384$ & Loss & 23072522 & $\mathrm{q} 23.1-\mathrm{q} 25$ & 1626 \\
\hline $\operatorname{chr} 12: 10,914,787-11,201,643$ & Loss & 286857 & p13.2 & 17 \\
\hline chr12:11,201,643-11,831,298 & High copy gain & 629656 & $\mathrm{p} 13.2$ & 39 \\
\hline chr12:33,409,429-35,400,000 & Loss & 1990572 & $\mathrm{p} 11.1-\mathrm{q} 11$ & 57 \\
\hline chr12:100,808,565-101,022,195 & Gain & 213631 & $\mathrm{q} 23.2$ & 13 \\
\hline $\operatorname{chr} 13: 17,928,209-34,651,641$ & High copy gain & 16723433 & $\mathrm{q} 11-\mathrm{q} 13.2$ & 1132 \\
\hline $\operatorname{chr} 13: 34,651,641-34,923,584$ & Gain & 271944 & $\mathrm{q} 13.2-\mathrm{q} 13.3$ & 17 \\
\hline
\end{tabular}


Table IV. Continued

\begin{tabular}{|c|c|c|c|c|}
\hline Chromosomal region & Copy number aberration & Length (bp) & Cytoband & No. of probes \\
\hline chr13:34,923,584-49,660,630 & High copy gain & 14737047 & $\mathrm{q} 13.3-\mathrm{q} 14.3$ & 927 \\
\hline chr13:49,660,630-49,890,816 & Gain & 230187 & $\mathrm{q} 14.3$ & 14 \\
\hline chr13:49,890,816-114,142,980 & High copy gain & 64252165 & $\mathrm{q} 14.3-\mathrm{q} 34$ & 3468 \\
\hline chr14:19,242,599-19,473,021 & Loss & 230423 & $\mathrm{q} 11.2$ & 13 \\
\hline chr14:19,758,344-21,385,999 & Loss & 1627656 & $\mathrm{q} 11.2$ & 127 \\
\hline $\operatorname{chr} 14: 21,385,999-21,678,310$ & Gain & 292312 & $\mathrm{q} 11.2$ & 34 \\
\hline chr14:21,678,310-22,073,646 & Homozygous copy loss & 395337 & $\mathrm{q} 11.2$ & 43 \\
\hline chr14:22,073,646-54,510,912 & Loss & 32437267 & $\mathrm{q} 11.2-\mathrm{q} 22.3$ & 1849 \\
\hline chr14:61,276,314-88,287,948 & High copy gain & 27011635 & $\mathrm{q} 23.2-\mathrm{q} 31.3$ & 1613 \\
\hline chr14:88,287,948-90,535,004 & Gain & 2247057 & $\mathrm{q} 31.3-\mathrm{q} 32.12$ & 132 \\
\hline $\operatorname{chr} 14: 98,445,434-105,601,857$ & High copy gain & 7156424 & $\mathrm{q} 32.2-\mathrm{q} 32.33$ & 526 \\
\hline chr14:105,700,924-106,368,585 & High copy gain & 667662 & $\mathrm{q} 32.33$ & 40 \\
\hline $\operatorname{chr} 15: 20,145,866-30,712,202$ & Loss & 10566337 & $\mathrm{q} 11.2-\mathrm{q} 13.3$ & 545 \\
\hline $\operatorname{chr} 15: 63,566,907-63,826,238$ & Loss & 259332 & $\mathrm{q} 22.31$ & 16 \\
\hline chr16:0-1,998,049 & Gain & 1998050 & p13.3 & 122 \\
\hline chr16:2,074,844-23,832,350 & Gain & 21757507 & $\mathrm{p} 13.3-\mathrm{p} 12.1$ & 1434 \\
\hline $\operatorname{chr} 16: 23,832,350-24,085,795$ & Loss & 253446 & p12.1 & 15 \\
\hline chr16:24,085,795-29,582,504 & Gain & 5496710 & $\mathrm{p} 12.1-\mathrm{p} 11.2$ & 305 \\
\hline chr16:29,582,504-33,746,468 & Loss & 4163965 & $\mathrm{p} 11.2$ & 227 \\
\hline $\operatorname{chr} 16: 33,746,468-35,006,622$ & Gain & 1260155 & $\mathrm{p} 11.2-\mathrm{p} 11.1$ & 58 \\
\hline chr16:44,945,309-55,455,741 & Gain & 10510433 & $\mathrm{q} 11.2-\mathrm{q} 13$ & 647 \\
\hline chr16:56,876,211-76,791,921 & Gain & 19915711 & $\mathrm{q} 21-\mathrm{q} 23.1$ & 1270 \\
\hline $\operatorname{chr} 16: 77,529,554-88,827,254$ & Gain & 11297701 & $\mathrm{q} 23.1-\mathrm{q} 24.3$ & 718 \\
\hline $\operatorname{chr} 17: 4,964,674-5,005,652$ & Loss & 40979 & p 13.2 & 53 \\
\hline $\operatorname{chr} 17: 6,030,004-6,459,217$ & Loss & 429214 & p13.2 & 25 \\
\hline $\operatorname{chr} 17: 20,079,654-20,634,224$ & Loss & 554571 & $\mathrm{p} 11.2$ & 28 \\
\hline $\operatorname{chr} 17: 22,200,000-70,815,509$ & Loss & 48615510 & $\mathrm{q} 11.1-\mathrm{q} 25.1$ & 3395 \\
\hline chr17:74,616,873-75,422,920 & Loss & 806048 & $\mathrm{q} 25.3$ & 39 \\
\hline chr18:19,868,443-20,151,388 & Loss & 282946 & $\mathrm{q} 11.2$ & 17 \\
\hline chr19:10,645,176-10,984,732 & Loss & 339557 & $\mathrm{p} 13.2$ & 46 \\
\hline $\operatorname{chr} 19: 47,876,805-48,456,771$ & Loss & 579967 & q13.31 & 27 \\
\hline chr19:51,972,368-55,041,795 & Loss & 3069428 & $\mathrm{q} 13.32-\mathrm{q} 13.33$ & 206 \\
\hline chr19:55,041,795-59,364,356 & Gain & 4322562 & $\mathrm{q} 13.33-\mathrm{q} 13.42$ & 362 \\
\hline chr19:59,364,356-59,743,803 & High copy gain & 379448 & $\mathrm{q} 13.42$ & 23 \\
\hline chr19:59,743,803-63,811,651 & Gain & 4067849 & $\mathrm{q} 13.42-\mathrm{q} 13.43$ & 242 \\
\hline chr20:7,042,589-8,048,700 & High copy gain & 1006112 & $\mathrm{p} 12.3$ & 56 \\
\hline chr20:27,100,000-28,266,142 & Gain & 1166143 & $\mathrm{q} 11.1$ & 10 \\
\hline chr20:29,297,076-39,079,714 & Loss & 9782639 & $\mathrm{q} 11.21-\mathrm{q} 12$ & 714 \\
\hline chr20:39,079,714-39,209,853 & Homozygous copy loss & 130140 & q12 & 19 \\
\hline chr20:39,209,853-62,435,964 & Loss & 23226112 & $\mathrm{q} 12-\mathrm{q} 13.33$ & 1760 \\
\hline chr22:14,433,500-18,072,209 & Gain & 3638710 & $\mathrm{q} 11.1-\mathrm{q} 11.21$ & 238 \\
\hline chr22:18,529,725-28,719,750 & Gain & 10190026 & $\mathrm{q} 11.21-\mathrm{q} 12.2$ & 730 \\
\hline chr22:28,719,750-29,265,348 & Loss & 545599 & $\mathrm{q} 12.2$ & 33 \\
\hline chr22:29,265,348-40,253,100 & Gain & 10987753 & $\mathrm{q} 12.2-\mathrm{q} 13.2$ & 846 \\
\hline chr22:44,546,688-44,803,212 & High copy gain & 256525 & $\mathrm{q} 13.31$ & 16 \\
\hline chrX:0-59,500,000 & Loss & 59500001 & $\mathrm{p} 22.33-\mathrm{q} 11.1$ & 3431 \\
\hline chrX:61,697,828-95,798,355 & Loss & 34100528 & $\mathrm{q} 11.1-\mathrm{q} 21.33$ & 1923 \\
\hline chrX:95,798,355-96,306,484 & Homozygous copy loss & 508130 & $\mathrm{q} 21.33$ & 33 \\
\hline chrX:96,306,484-101,646,251 & Loss & 5339768 & $\mathrm{q} 21.33-\mathrm{q} 22.1$ & 288 \\
\hline chrX:101,646,251-154,913,754 & Homozygous copy loss & 53267504 & $\mathrm{q} 22.1-\mathrm{q} 28$ & 3033 \\
\hline
\end{tabular}

highest number of breakpoints were observed on chromosomes 1 and 4, whereas chromosomes 18 and 21 had the lowest; in fact, there were no unbalanced breakpoints on chromosome 21 and only two on chromosome 18 . The long arm of chromosome 4 had a complex pattern of alternating copy number changes (Figure 4C), which is compatible with chromothripsis (47). Chromothripsis has been invoked to explain clusters of gross chromosomal rearrangements in a 
wide variety of tumor types (48-52) but has not previously been described in a CPT-resistant cell line.

The detailed karyotype findings and the highly significant number of increased DNA break points generated in CPT-K5 cells not only indicates that the prolonged CPT inhibition of TOP1 at sublethal cellular doses is associated with the acquisition of major chromosomal and genomic reorganization both in terms of numerical and structural aberrations, but also that some chromosomes are unaffected. Absence of genomic or chromosomal aberrations suggests that these chromosomes or chromosomal regions might be lacking CPT-involved targets, and that these chromosomes or regions may contain genes of importance so only cells without aberrations affecting these genes may survive or that they have been repaired with great accuracy. This could be due to the essential functions of genes in those regions. The acquisition of major chromosomal reorganizations may at some point have resulted from DSBs, which in turn may have resulted from formation of TOP1-cc that were repaired erroneously, giving rise to copy number alterations, perhaps providing selective growth advantages.

Genomic copy number changes in CPT-K5 cells. To specifically address gene dosage changes that might be involved in generating highly stable CPT resistance, we closely examined different chromosomal locations harboring genes that are known to be involved in maintaining cellular and genomic homeostasis (53). Resistance of cancer cells to CPT is multifactorial, and five major mechanisms may account for cellular CPT resistance $(6,53-55)$ : i) reduced TOP1 activity, either by reduced specific activity or a reduced cellular amount $e . g$. due to reduced gene dosage; ii) TOP1 mutations that render the enzyme drug-resistant; iii) reduced intracellular active drug content by decreased drug influx or increased drug efflux; iv) resistance to apoptosis; and $\mathrm{v}$ ) efficient repair of TOP1-cc by the cell.

A first line of defense for a cell against CPT-induced damage is down-regulation of its TOP1 activity, thereby reducing TOP1cc $(55,56)$. Our subtractive oligo-based aCGH analysis revealed that the gene dosage of the TOP1 locus was diminished by a factor of approximately 1.7, which was confirmed by FISH (Figure 5). The loss of TOP1 gene copy numbers correlated with a reduced level of cellular TOP1 protein in CPT-K5 cells (Figure 2). Other studies have shown that a copy number change of the TOP1 gene correlates with the cellular amount of enzyme and seems to be a common mechanism contributing to CPT resistance (56). By CGH analysis of the CPT-resistant cell lines HT-29/CPT, A549/CPT and st-4/CPT, a reduced DNA copy number of TOP1 was shown together with a reduced relative expression of TOP1 (44). In our subtractive oligo-based aCGH analysis, we further screened for copy number changes of other type I topoisomerases (TOPIMT, TOP3A and TOP3B) and type II topoisomerases (TOP2A, TOP $2 B$ and TOPOVIA (also known as $S$. cerevisiae, homolog of, SPO11). We observed that TOP2A and SPO11 exhibited large losses, and loci of TOP3B and TOP2B were gained, while TOP3A and TOP1MT displayed no copy number change between the CPT-K5 and RPMI-8402 cells (Table IV).

Another line of defense for a cell to resist the effects of CPT is through the acquisition of single nucleotide mutations of TOP1 thereby preventing the action of CPT on TOP1-cc [reviewed in (57)] (Table III). We previously showed that CPT-K5 harbors mutated TOP 1 containing the Asp533Gly mutation (34). These types of mutations, however, cannot be revealed by oligo-based aCGH analysis.

Reduced intracellular CPT concentration is a third important way to reduce the formation of devastating TOP1-cc. One of the major mechanisms responsible for multidrug resistance in cancer chemotherapy is overexpression of some members of the ATP-binding cassette (ABC) transporter superfamily, including $\mathrm{ABCB} 1, \mathrm{ABCC} 1$ and $\mathrm{ABCG} 2$, resulting in decreased intracellular levels of drugs [reviewed in (58)]. In mammalian cells, expression of $\mathrm{ABC}$ transporters such as Pgp (ABCB1) and $\mathrm{ABCG} 2$ confers resistance to $\mathrm{CPT}$ and its derivatives (59$61)$. Gene amplification is a major contributor to increased

Figure 5. Fluorescence in situ hybridization (FISH) validation of copy number changes at specific genomic regions important for the camptothecin resistance in CPT-K5 cells. Left hand-side panel: Genomic profiles of chromosome 20 (upper panel), chromosome 4 (middle panel) and chromosome 14 (lower panel) together with their respective ideograms beneath. Magnified genomic profile views of corresponding altered chromosomal regions are given below chromosome 20, chromosome 4, and chromosome 14 indicating deleted region at 20q12 containing topoisomerase 1 (TOP1) gene, highly amplified region at 4q22.1 containing ATP-binding cassette sub-family $G$ member 2 (ABCG2) gene and amplified region at $14 q 31.3 q 32.11$ containing the tyrosyl-DNA phosphodiesterase 1 (TDP1) gene, respectively. Blue and red bars around the ideograms indicate regions of gains and losses, respectively. Regions with high gains and losses are indicated by double bars in their respective color. A yellow bar in the copy number profile of chromosome 14 indicates the region of gain in the CR1-CR2/MMRU cell lines (see Table III). Right hand-side panel: FISH analyses confirm the genomic array comparative genomic hybridization (aCGH) findings in the RPMI-8402 and CPT-K5 cell lines on interphase nuclei with hybridization signals using the following probe sets as indicated by red and green marks on the respective ideograms in the left hand-side panel: i) Bacterial artificial chromosome (BAC)-based probe containing the TOP1 gene (red) and centromere 20 probe (green); ii) BAC-based probe RP11-368G2 (green) containing the ABCG2 gene together with centromere 4 probe (red) to the right metaphase spreads represented by partial karyograms of chromosomes 4 and 12; and iii) BAC-based probe RP11-213O13 (red) containing the TDP1 gene together with subtelomeric 14-qter probe (green) - to the right metaphase spreads represented by partial karyograms of derivative chromosomes $11(\operatorname{der}(11) t(11 ; 14))$ and 15 (der(15)t(14;15)) for RPMI-8402 and partial karyograms of derivative chromosomes $5(\operatorname{der}(5) t(5 ; 14)(q 35 ; q 32))$ and 14 for CPT-K5. 

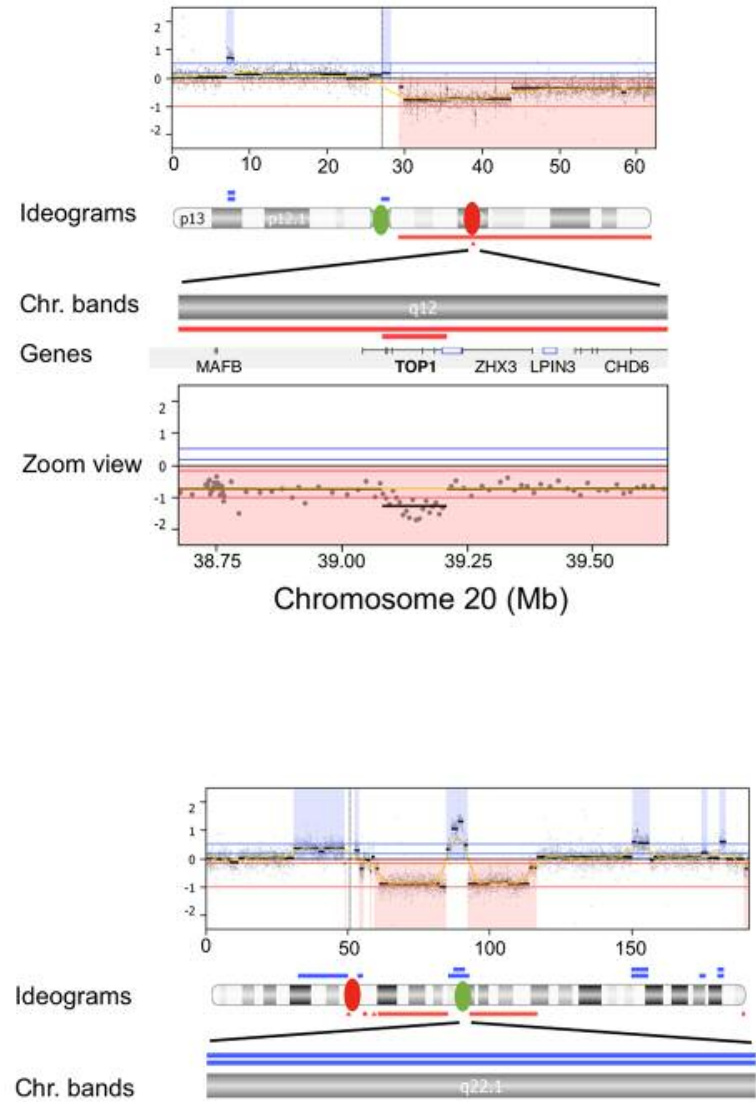

Chr. bands

Genes

Zoom view
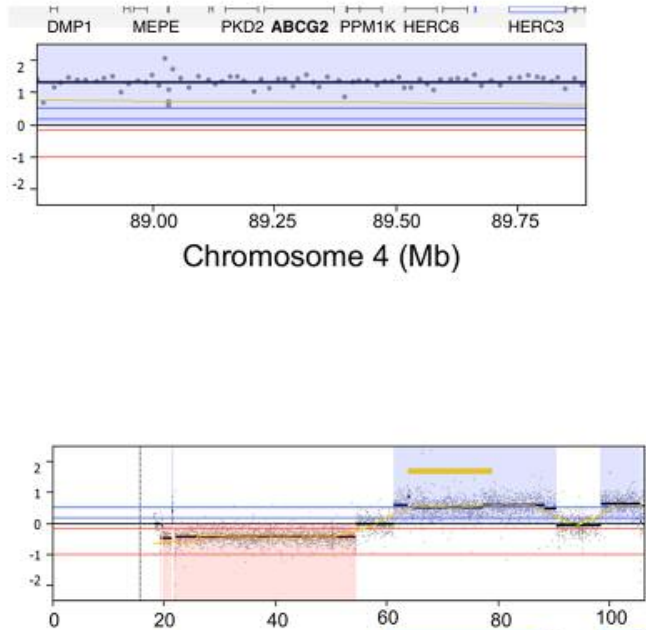

Ideograms

Chr. bands

Genes

Zoom view
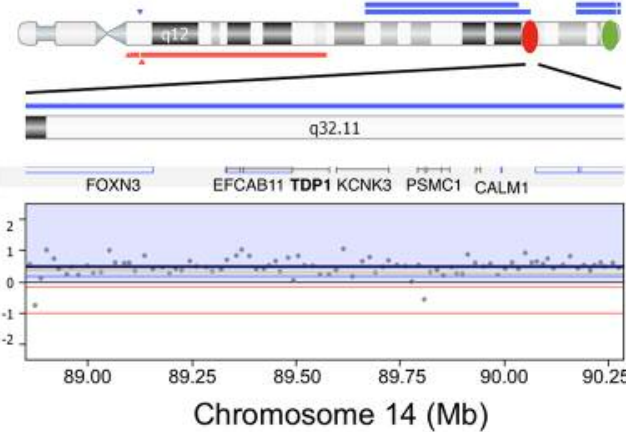

RPMI-8402

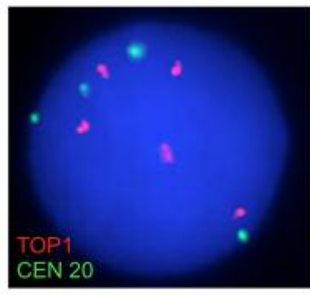

CPT-K5

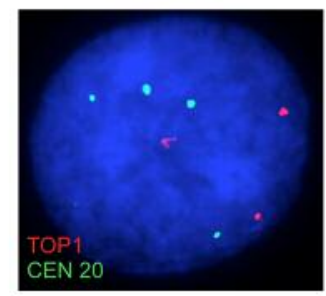

RPMI-8402
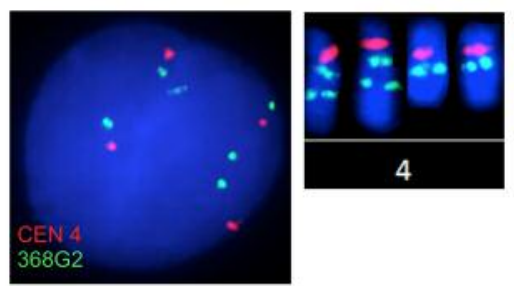

CPT-K5
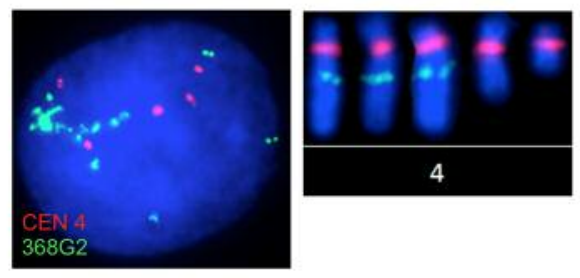

12
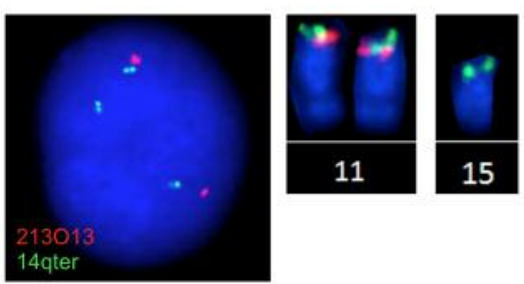

CPT-K5

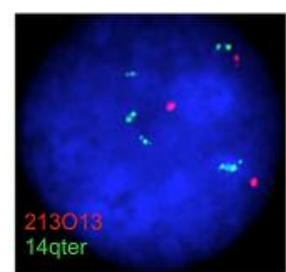

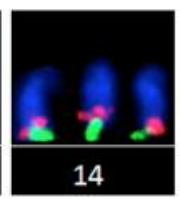


Table V. Copy number findings of key genes involved in DNA repair pathways and cell-cycle arrest in CPT-K5 cells relative to RPMI-8402 cells.

\begin{tabular}{|c|c|c|c|c|}
\hline HGNC-approved gene sy & Function & Cytoband & Pos. (hg18) & Copy number \\
\hline \multicolumn{5}{|c|}{ Proteasome-dependent TOP1 degradation pathway/phosphodiesterase pathway for TOP1-cc repair of single-ended DSB } \\
\hline PARP1 & DSB recognition, $X R C C 1$ and $T D P 1$ recruitment & $1 \mathrm{q} 42.12$ & $224,615,015-224,662,424$ & Loss \\
\hline TDP1 & Hydrolyze the tyrosyl-DNA link in Top1-DNA complex & $14 \mathrm{q} 32.11$ & $89,491,999-89,580,861$ & High gain \\
\hline$X R C C 1$ & DNA binding & $19 \mathrm{q} 13.31$ & $48,739,304-48,771,570$ & $\mathrm{nc}$ \\
\hline PTEN & Phosphatase, negative regulator of PI3K/AKT pathway & $10 \mathrm{q} 23.31$ & $89,613,175-89,718,512$ & Loss \\
\hline$P N K P$ & End processing & $19 q 13.33$ & $55,056,273-55,062,630$ & Gain \\
\hline$A P E X 1$ or $A P E 1$ & Apurinic/apyrimidinic endodeoxyribonuclease 1 & $14 \mathrm{q} 11.2$ & $19,993,130-19,995,766$ & Loss \\
\hline$P O L B$ & DNA polymerase beta & $8 \mathrm{p} 11.21$ & $42,315,187-42,348,470$ & $\mathrm{nc}$ \\
\hline$P R K D C$ & & $8 \mathrm{q} 11.21$ & $48,848,222-49,035,296$ & $\mathrm{nc}$ \\
\hline \multicolumn{5}{|c|}{ Proteasome-independent pathway/endonuclease pathway for TOP1-cc repair of single-ended DSB } \\
\hline ERCC1 & Interacts with ERCC4 to form endonuclease & $19 \mathrm{q} 13.32$ & $50,608,532-50,618,642$ & $\mathrm{nc}$ \\
\hline ERCC4 or $X P F$ & 3'-Flap endonuclease subunit & $16 \mathrm{p} 13.12$ & $13,921,515-13,953,706$ & Gain \\
\hline RPAl & Replication protein A1 subunit & $17 \mathrm{p} 13.3$ & $1,680,023-1,749,598$ & $\mathrm{nc}$ \\
\hline RPA2 & Replication protein A2 subunit & $1 \mathrm{p} 35.3$ & $28,090,636-28,223,823$ & $\mathrm{nc}$ \\
\hline RPA3 & Replication protein A3 subunit & $7 \mathrm{p} 21.3$ & $7,643,100-7,724,763$ & High gain \\
\hline POLD1 & Polymerase delta catalytic subunit A & $19 q 13.33$ & $55,579,405-55,613,083$ & Gain \\
\hline POLD2 & Polymerase delta catalytic subunit B & $7 \mathrm{p} 13$ & $44,120,811-44,129,672$ & Gain \\
\hline POLD3 & Polymerase delta catalytic subunit D & $11 \mathrm{q} 13.4$ & $73,981,277-74,031,413$ & Loss \\
\hline POLD4 & Polymerase delta catalytic subunit A & $11 \mathrm{q} 13.1$ & $66,875,595-66,877,593$ & Loss \\
\hline FEN1 & Flap structure-specific endonuclease 1 & $11 \mathrm{q} 12.2$ & $61,316,726-61,321,286$ & Loss \\
\hline LIGI & DNA ligase 1 & $19 \mathrm{q} 13.32$ & $53,130,515-53,365,372$ & Loss \\
\hline$S L X 4$ & Structure-specific endonuclease subunit & $16 \mathrm{p} 13.3$ & $3,571,185-3,601,608$ & Gain \\
\hline \multicolumn{5}{|l|}{ HR \& NHEJ } \\
\hline ATM & Binds to MRN complex, phosphorylates $C H K 2$ & $11 \mathrm{q} 22.3$ & $107,598,769-107,745,036$ & Loss \\
\hline$H 2 A F X$ & Activated by ATM, recruit further DNA repair components & $11 \mathrm{q} 23.3$ & $118,469,795-118,471,387$ & Loss \\
\hline MRE11 & Endonuclease, 3'-5' exonuclease, MRN complex & $11 \mathrm{q} 21$ & $93,790,115-93,866,688$ & Loss \\
\hline$N B N$ or $N B S 1$ & Adaptor, check point roles, MRN complex & $8 \mathrm{q} 21.3$ & $91,014,740-91,060,075$ & $\mathrm{nc}$ \\
\hline PARP1 & DSB recognition, MRN complex recruitment & $1 \mathrm{q} 42.12$ & $224,615,015-224,662,424$ & Loss \\
\hline RAD50 & ATPase/Scaffold, MRN complex & $5 q 31.1$ & $131,920,529-132,007,494$ & Loss \\
\hline \multicolumn{5}{|c|}{$x^{2}$} \\
\hline$B A R D 1$ & BRCA1-associated ring domain & $2 q 35$ & $215,301,520-215,382,673$ & Gain \\
\hline$B L M$ or $R E C Q L 3$ & Bloom syndrome, helicase & $15 q 26.1$ & $89,061,583-89,159,690$ & Gain \\
\hline BRCA1 & Mediator/adaptor, ubiquitin ligase & $17 \mathrm{q} 21.31$ & $38,449,840-38,530,994$ & Loss \\
\hline$B R C A 2$ & Recombination mediator, binds to RAD51 & $13 \mathrm{q} 13.1$ & $31,787,617-31,871,809$ & High gain \\
\hline$R B B P 8$ or $C t I P$ & Endonuclease; binds to BRCA1 & $18 \mathrm{q} 11.2$ & $18,767,293-18,860,447$ & $\mathrm{nc}$ \\
\hline DNA2 & DNA replication helicase 2 & $10 \mathrm{q} 21.3$ & $69,843,827-69,901,885$ & Gain \\
\hline EXO1 & 5'-3' Exonuclease & $1 \mathrm{q} 43$ & $240,078,158-240,119,671$ & Loss \\
\hline$L I G 1$ & ATP-dependent DNA ligase & $19 \mathrm{q} 13.32$ & $53,310,515-53,365,372$ & Loss \\
\hline$P A L B 2$ & Partner and localizer of BRCA2 & $16 \mathrm{p} 12.1$ & $23,521,984-23,560,179$ & Gain \\
\hline$P O L D$ & See above for POLD1-4 & - & - & - \\
\hline POLE & Catalytic subunit DNA polymerase epsilon & $12 q 24.33$ & $131,710,421-131,774,018$ & $\mathrm{nc}$ \\
\hline RAD51 & Recombinase, homology pairing & $15 q 15.1$ & $38,774,651-38,811,648$ & $\mathrm{nc}$ \\
\hline RAD52 & Mediator of repair & $12 \mathrm{p} 13.33$ & $904,877-912,503$ & $\mathrm{nc}$ \\
\hline$A T R X$ or $R A D 54$ & Recombinase, D-loop formation & $\mathrm{Xq} 21.1$ & $76,647,012-76,928,375$ & Loss \\
\hline RPA & See above for $R P A 1-3$ & - & - & - \\
\hline \multicolumn{5}{|l|}{ Classic NHEJ } \\
\hline$A P T X$ & End processing & $9 \mathrm{p} 13.3$ & $32,962,608-32,991,626$ & Loss \\
\hline$A P L F$ & End processing & $2 \mathrm{p} 14$ & $68,548,246-68,660,798$ & $\mathrm{nc}$ \\
\hline LIG4 & DNA ligase 4 , complexes with XRCC4 & $13 \mathrm{q} 33.3$ & $107,657,793-107,665,883$ & High gain \\
\hline$N H E J 1$ or $X L F$ & Scaffold protein & $2 \mathrm{q} 35$ & $219,648,290-219,733,831$ & Gain \\
\hline$P N K P$ & End processing & $19 q 13.33$ & $55,056,273-55,062,630$ & Gain \\
\hline$P R K D C$ or $D N A-P K C S$ & DSB-responsive PIKK family protein kinase & $8 \mathrm{q} 11.21$ & $48,848,222-49,035,296$ & $\mathrm{nc}$ \\
\hline POLL or DNA-Pol $\mu$ & End processing, gap filling & $10 \mathrm{q} 24.32$ & $103,328,629-103,337,963$ & Gain \\
\hline POLM or DNA-Pol $\mu$ & End processing, gap filling & $7 \mathrm{p} 13$ & $44,078,372-44,088,607$ & Gain \\
\hline XRCC4 & Scaffold protein & $5 \mathrm{q} 14.2$ & $82,409,073-82,685,335$ & $\mathrm{nc}$ \\
\hline XRCC 5 or $K u 80$ & dsDNA end binding, resection inhibition & $2 q 35$ & $216,682,377-216,779,248$ & Gain \\
\hline XRCC6 or Ku70 & dsDNA end binding, resection inhibition & $22 q 13.2$ & $40,347,241-40,389,998$ & $\mathrm{nc}$ \\
\hline
\end{tabular}


Table V. Continued

\begin{tabular}{|c|c|c|c|c|}
\hline HGNC-approved gene symbol & Function & Cytoband & Pos. (hg18) & Copy number \\
\hline \multicolumn{5}{|l|}{ Alternative NHEJ } \\
\hline$R B B P 8$ or $C t I P$ & Nuclease; binds to BRCA1 & $18 \mathrm{q} 11.2$ & $18,767,293-18,860,447$ & $\mathrm{nc}$ \\
\hline$P O L B$ & Gap filling & $8 \mathrm{p} 11.21$ & $42,315,187-42,348,470$ & $\mathrm{nc}$ \\
\hline$X R C C 1$ & DNA binding & $19 \mathrm{q} 13.31$ & $48,739,304-48,771,570$ & $\mathrm{nc}$ \\
\hline LIG3 & DNA ligase 3, complexes with XRCC1 & $17 \mathrm{q} 12$ & $30,331,651-30,356,201$ & Loss \\
\hline$W R N$ & DSB repair mediator, Helicase 3'-5 exonuclease & $8 \mathrm{p} 12$ & $31,010,320-51,150,819$ & $\mathrm{nc}$ \\
\hline \multicolumn{5}{|l|}{ Mismatch repair } \\
\hline MLH1 & Forms a heterodimer with PSM2 & $3 \mathrm{p} 22.2$ & $37,009,983-37,067,341$ & $\mathrm{nc}$ \\
\hline$M L H 3$ & Forms heterodimer with MLH1 & $14 \mathrm{q} 24.3$ & $74,550,220-74,587,988$ & High gain \\
\hline MSH2 & Forms heterodimer with MSH6 & $2 \mathrm{p} 16.3$ & $47,483,767-47,563,864$ & $\mathrm{nc}$ \\
\hline MSH3 & Forms heterodimer with MSH3 & $5 \mathrm{q} 14.1$ & $79,986,050-80,208,390$ & $\mathrm{nc}$ \\
\hline MSH6 & Forms heterodimer with MSH2 & $2 \mathrm{p} 16.3$ & $47,863,725-47,887,596$ & Loss \\
\hline PMS1 & Forms heterodimer with MLH1 & $2 \mathrm{q} 32.2$ & $190,357,056-190,450,600$ & $\mathrm{nc}$ \\
\hline$P M S 2$ & Forms heterodimer with MLH1 & $7 \mathrm{p} 22.1$ & $5,979,396-6,015,263$ & Gain \\
\hline \multicolumn{5}{|l|}{ Cell-cycle arrest } \\
\hline CHK1 & Phosphorylated by ATR, $\mathrm{G}_{2} / \mathrm{M}$ cell-cycle arrest & $11 \mathrm{q} 24.2$ & $125,001,854-125,030,850$ & Loss \\
\hline CHK2 & Phosphorylated by ATM, $\mathrm{G}_{1}$ cell-cycle arrest & $22 \mathrm{q} 12.1$ & $27,413,731-27,460,715$ & Gain \\
\hline TP53 & $\mathrm{G}_{1}$ and $\mathrm{G}_{2}$ Cell cycle arrest & $17 \mathrm{p} 13.1$ & $7,512,445-7,531,588$ & $\mathrm{nc}$ \\
\hline
\end{tabular}

DSB: Double=strand break HR: homologous recombination; NHEJ: non-homologous end-joining; nc: no change.

expression of $\mathrm{ABCB} 1$ and $\mathrm{ABCG} 2$ in colorectal and breast cancer cells making them resistant towards the CPT-analog SN-38 and mitoxantrone $(62,63)$. Remarkably, we found that in the CPT-K5 cell line, the genes $A B C B 1$ and $A B C C 1$ are located in regions of copy number gain at $7 \mathrm{q} 21.12$ and 16p13.11, respectively, while $A B C G 2$ is in the region of highest copy gain at 4q22.1 (Figure 5, Table IV). The CPT-resistant cell lines HT-29/CPT and A549/CPT had amplified ABC transporter family genes (44). These observations indicate that copy numbers gains of $\mathrm{ABC}$ transporters are of importance in decreased intracellular CPT accumulation in CPT-K5 cells. It has been shown that $\mathrm{CPT}-\mathrm{K} 5$ is multidrug resistant e.g. it is also resistant to topoisomerase II inhibitors (64). This observation is in line with the findings that there are many drugs that are substrates for the ABCG2 transporter, including topoisomerase II inhibitors (e.g. mitoxantrone, etoposide, daunorubicin, and doxorubicin), CPT analogs (e.g. topotecan, and irinotecan), tyrosine kinase inhibitors, antimetabolites, and many other drug types [reviewed in (58)]. Interestingly, a glioblastoma cell line, SF295, which became mitoxantroneresistant by exposure to step-wise increasing concentrations of the drug had a resulting $A B C G 2$ amplification by forming double minutes, which were later reintegrated into the genome at multiple chromosomal regions during subsequent selection steps (43). In the CPT-K5 cell line, we found that the $A B C G 2$ gene in addition to its location at $4 \mathrm{q} 22.1$ is highly amplified at a single chromosomal site on $\operatorname{der}(12) \mathrm{t}(4 ; 12)$ (Figure 5), suggesting a similar mechanism of amplification to that observed in the SF295 cell line. Taken together, these findings support the idea that $A B C G 2$ is one of the most important transporter genes in relation to CPT and its derivatives, which is in agreement with previous suggestions (65-67).

Alteration of apoptotic pathways is a fourth line of defense in influencing resistance to CPT. The biochemical pathways of apoptosis include pro-apoptotic and antiapoptotic proteins, which affect the cellular response to CPT as reviewed elsewhere $(7,68)$. A delicate balance between pro- and anti-apoptotic pathways has been proposed to provide alternative means of providing cancer cells with a selective advantage promoting chemoresistance (69). Apoptosis involves a complex network of many proteins of which the proteins encoded by tumour protein p53 (TP53), inhibitor of apoptosis, $\mathrm{X}$-linked $(X I A P)$ and baculoviral IAP repeat-containing protein 5 (BIRC5) play important roles in regulating apoptosis (70). TP53 plays an important role in sensitivity to CPT and apoptosis induced by CPT. When leukemia cells are deficient in p53 function, the cells are hypersensitive to CPT, whereas cells with normal functioning p53 are resistant to CPT $(71,72)$. In our study, we found that the copy number of TP53 was unchanged (Tables IV and V), which is in agreement with previous findings that normal TP53 is important for resistance to CPT and its derivatives. The anti-apoptotic genes XIAP and $B I R C 5$ possess a wide range of biological activities that promote cancer cell survival and proliferation to overcome endogenous and exogenous insults [reviewed in (68)]. We found CPT-K5 cells had loss of the XIAP gene and that $B I R C 5$ had no copy number change (Table IV).

A fifth line of defense against CPT is efficient repair of CPTinduced DNA damage by the cell (53). Although the 


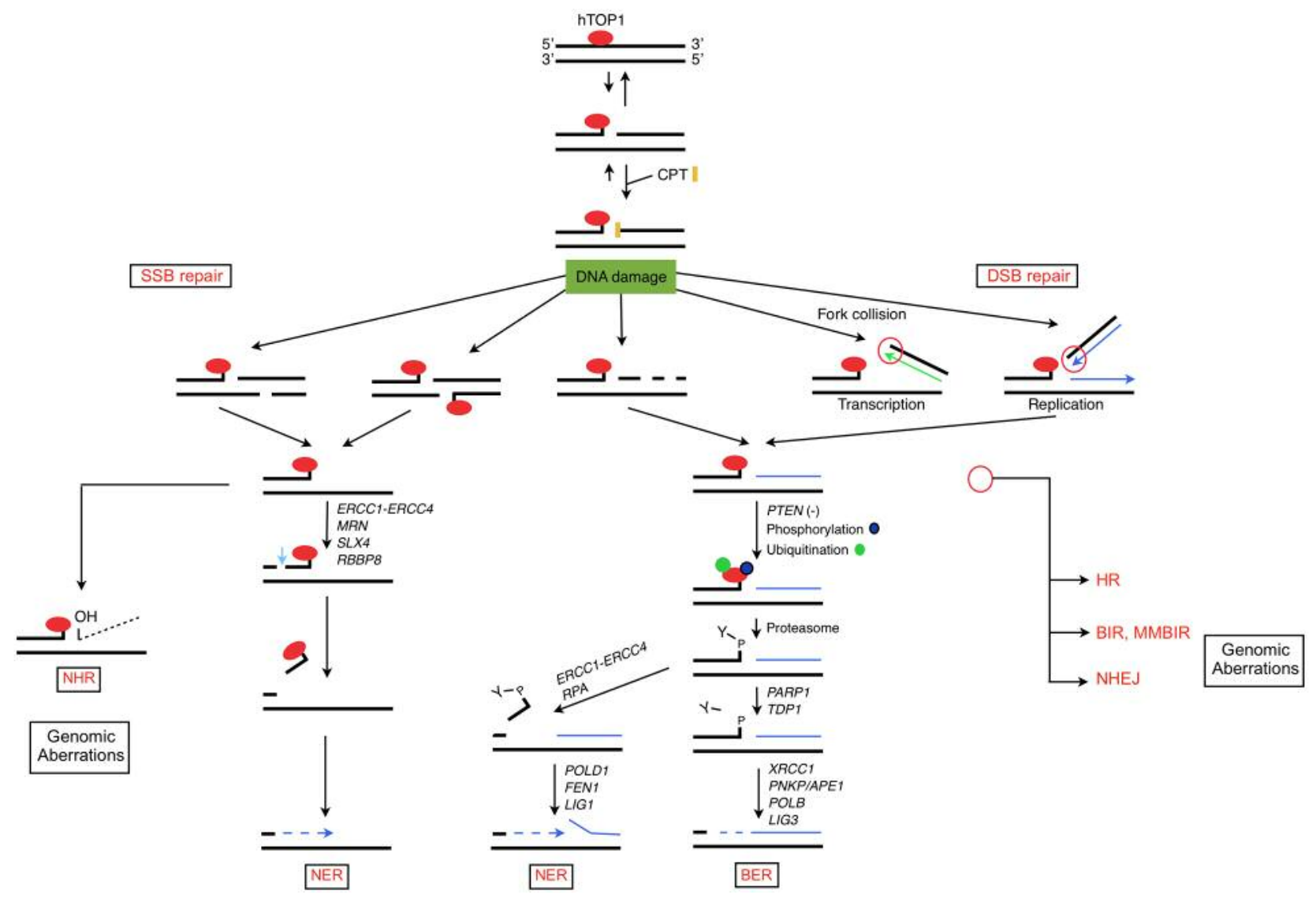

Figure 6. Schematic overview of mechanisms implicated in repair of camptothecin (CPT)-induced DNA damage. BER: Base excision repair; BIR: breakage-induced replication; CPT: camptothecin or its derivatives; DSB: double-strand break; HR: homologous recombination; MMBIR: microhomology-mediated BIR; MRN: meiotic recombination 11 (MRE11)/DNA repair protein RAD5O(RAD50)/nibrin (NBS1) complex; NER: nucleotide excision repair; NHEJ: non-homologous end-joining; NHR: non-homologous recombination; PTEN(-) indicates phosphatase and tensin homolog deficiency; SSB: single-strand DNA break. Open red circle indicates fork collision and repair mechanisms; Y-P: 3'-phosphotyrosyl.

mechanisms implicated in repair of TOP1-cc have been widely studied they still remain largely elusive (73-78). The repair of this rather unique form of DNA damage involves different pathways (Figure 6) that cooperate to remove the TOP1-cc and restore intact DNA, thus allowing the resumption of physiological cellular functions including replication and transcription. An important step in the repair of TOP1-cc is degradation of DNA-bound TOP1 (76). Furthermore, it has been shown that cells that rapidly degrade TOP1 are resistant to CPT, while cells that fail to degrade TOP1 are sensitive to CPT $(75,79)$. TOP1 covalently stalled on DNA is degraded via a ubiquitin-26S proteasome pathway into a small peptide with a tyrosyl residue attached to the 3'-end of the nicked DNA (75, 76). A recent finding suggests that phoaphatase and tensin homolog (PTEN) availability may determine the fate of cells harboring CPT-induced DNA damage by regulating activity of DNA-dependent protein kinase (PRKDC) kinase, which phosphorylates TOP1 on serine 10 (79). It was found that
PTEN deletion ensures higher TOP1 serine 10 phosphorylation leading to rapid TOP1 degradation and CPT resistance. PRKDC-dependent phosphorylation of TOP1 in complex with DNA seems to be a prerequisite for ubiquitinylation, which in turn is required for proteasomal degradation (79).

Another important aspect of the repair of CPT-induced DNA damage is the fate of stalled or collapsed replication or transcription fork complexes which are generated by CPT (80). Colliding replication forks on the leading strand for DNA synthesis or transcription on the template strand convert CPT-stabilized TOP1-cc into devastating DSBs if unrepaired. Break-induced replication (BIR) is a homologous recombination pathway which was recently identified as serving for repair of collapsed or broken replication forks [reviewed in $(81,82)$ ]. Another more recent BIR-related pathway called micro-homology-mediated BIR has been proposed to explain copy number alterations, complex chromosomal rearrangements and microsatellite expansion 


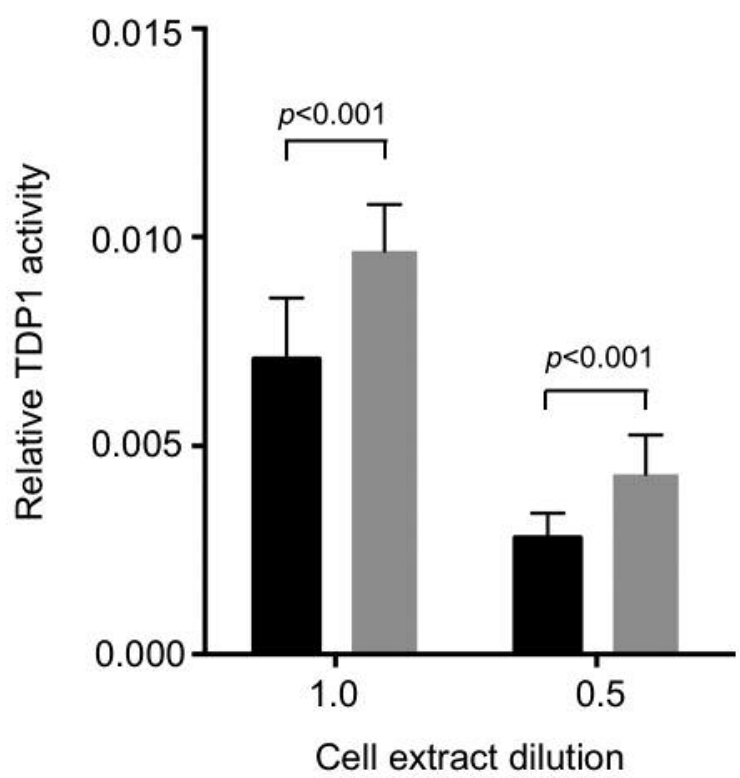

Figure 7. Bar chart showing the mean of the results obtained when measuring relative tyrosyl-DNA phosphodiesterase 1 (TDP1) activity in whole-cell extracts from $1.0 \times 10^{6}$ and $0.5 \times 10^{6} \mathrm{RPMI}-8402$ (black bars) and CPT-K5 (grey bars) cells, as indicated in the figure, in three independent repetitions. Relative TDP1 activity in CPT-K5 cells was increased by a factor of $1.42(p<0.001$; unpaired $t$-test $)$. The error bars indicate standard deviation.

associated with cancer and various other diseases in humans (81-83). It is beyond the scope of this study to describe these processes in more detail, as excellent reviews exist $(81,82)$.

A summary of the genes involved in the repair processes described above is given in Table $\mathrm{V}$, which also provides information about copy number changes affecting these genes in the CPT-K5 cell line. Interestingly, important genes involved in the repair of TOP1-induced DNA damage had copy number changes. Firstly, the PTEN gene, an upstream effector of the proteasomal pathway, had a copy number loss. Secondly, a 50\% increase in copy number of the TDP1 gene, which was confirmed by FISH analysis (Figure 5), and a 1.42fold higher relative activity of TDP1 (Figure 7) were identified. Both of these observations are in agreement with the recent findings by Ando et al. (79) suggesting that PTEN deletion ensures higher TOP1 serine 10 phosphorylation by PRKDC, favoring rapid TOP1 degradation and CPT resistance. It might be interesting in future studies to determine PTEN expression or the level of phosphorylated serine 10 in TOP1 in the CPT-K5 cell line and investigate whether TOP1 is more degraded in response to CPT in CPT$\mathrm{K} 5$ cells. A previous BAC-based aCGH analysis on the irinotecan-resistant cell lines CR1 and CR2, derived from parental melanoma MMRU cell lines, showed a gain of the region $14 \mathrm{q} 23.2$ to $\mathrm{q} 31.1$ (21). The amplified region in that study is within the region gained at 14q23.2-q32.12 observed in CPT-K5 cells (Table IV; Figure 5) but amplification in the $\mathrm{CR} 1$ and CR2 cells did not include the TDP1 gene. A major difference between the CPT-K5 and the CR1/CR2 cell lines is that the latter needs CPT to be present for the cells to conserve their CPT resistance as opposed to CPT-K5 cells, which are stably CPT-resistant in the absence of CPT. This difference may influence the cellular dynamics of e.g. DNA repair.

The DNA mismatch repair (MMR) system also plays an important role in maintaining genomic stability (84). The main genes involved in MMR include, E. coli homolog of MutL (MLH1), MLH2, E. coli homolog of MutS (MSH2), MSH3, MSH6, postmeiotic segregation increased, $S$. cerevisiae 1 (PMS1), and PMS2. Defects in any of these genes result in microsatellite instability (85) and repeat expansions (86). It was shown in one study that $M S H 2$ deficiency results in a higher sensitivity to CPT, while loss of $M L H 1$ results in CPT resistance (87). In the CPT-K5 cell line, we observed a gain of MLH3 and PMS2, and a 3'-partial loss of MSH6, while there were no copy number changes in the other MMR genes (Table V). Although only few studies exist on MMR and CPT sensitivity, gain of $M L H 3$ located at $14 \mathrm{q} 24.3$ might be a recurrent rearrangement in CPT-resistant cells as it was also observed in CPT-resistant MMRU cells (21).

A slower growth rate has been reported in several CPTresistant cell lines $(55,11,22)$, although this does not seem to be a major mechanism of resistance to TOP1 inhibitors (55). It may, however, be a reminiscence of altered properties as a result of obtaining CPT resistance because cell-cycle checkpoint arrest is important to allow time for repair and to prevent progression of replication. CPT-induced DNA damage activates $S$. pombe homolog of checkpoint 1 (CHK1) and CHK2 checkpoint kinases (88). The two independent CPT-resistant colorectal cancer cell lines derived from HT-29 and HCT-116 had an approximately 30\% increased doubling time (22). Increased basal levels of H2A histone family, member $\mathrm{X}(\gamma-\mathrm{H} 2 \mathrm{AX})$ and activated CHK2 accompanied these findings, without notable changes in the level of CHK1. Consistent with these findings, the CPT-K5 cell line has an increased generation doubling time (approximately 100\% increase) (11) and amplification of the $C H K 2$ gene together with a relative loss of CHK1 (Table V).

STR profiling of RPMI-8402 and CPT-K5. Because of the major cytogenetic and genomic differences between RPMI8402 and CPT-K5 cells, we wanted to examine whether STRs differ between the two cell lines. STRs are microsatellites with repetitive sequences characterized by a variable number of repeated short sequence elements of 2-6 bp in length as a unit (e.g. di-, tri-, and tetra-sequences). They are highly polymorphic between individuals and are especially used in forensic studies for human identification, and more recently for authentication of human cell lines $(89,90)$. 
Table VI. Short tandem repeat (STR) profiling of RPMI-8402 and CPT-K5 cells using the AmpFISTR ${ }^{\circledR}$ Identifiler PCR amplification kit.

\begin{tabular}{|c|c|c|c|c|c|}
\hline \multirow[t]{2}{*}{ STR locus } & \multirow{2}{*}{$\begin{array}{c}\text { Chromosomal } \\
\text { location }\end{array}$} & \multicolumn{2}{|c|}{ STR alleles ${ }^{\mathrm{a}}$} & \multirow[t]{2}{*}{ Match } & \multirow{2}{*}{ Repeat unit ${ }^{b}$} \\
\hline & & RPMI-8402 & CPT-K5 & & \\
\hline TPOX* & $2 \mathrm{p} 25.3$ & 8 & 8 & M & $(\mathrm{AATG})_{6-14}$ \\
\hline \multirow[t]{4}{*}{$\mathrm{D} 2 \mathrm{~S} 1338$} & $2 q 35$ & 19 & 23 & $\mathrm{~m}$ & $(\mathrm{TGCC})_{6}(\mathrm{TTCC})_{11}$ \\
\hline & & 23 & 24 & & \\
\hline & & & 26 & & \\
\hline & & & $(27)$ & & \\
\hline \multirow[t]{3}{*}{ D3S1358 } & $3 \mathrm{p} 21.31$ & 14 & 14 & $\mathrm{~m}$ & TCTA $(\text { TCTG })_{2-3}(\text { TCTA })_{10-15}$ \\
\hline & & 16 & 15 & & \\
\hline & & & 16 & & \\
\hline \multirow[t]{3}{*}{ FGA } & $4 q 28$ & 23 & 21 & & $(\text { TTTC })_{3}$ TTTTTTCT $(\text { CTTT })_{7}$ CTCC $(\text { TTCC })_{2}$ \\
\hline & & & 22 & & \\
\hline & & & 24 & & \\
\hline \multirow[t]{3}{*}{ D5S818* } & $5 \mathrm{q} 23.2$ & 12 & 11 & $\mathrm{~m}$ & $(\mathrm{AGAT})_{7-15}$ \\
\hline & & 13 & 12 & & \\
\hline & & & 13 & & \\
\hline \multirow[t]{4}{*}{ CSF1PO } & $5 \mathrm{q} 33.1$ & 11 & 9 & $\mathrm{~m}$ & $(\mathrm{AGAT})_{5-16}$ \\
\hline & & 12 & $(10)$ & & \\
\hline & & & 11 & & \\
\hline & & & 12 & & \\
\hline \multirow{3}{*}{ D7S820* } & $7 q 21.11$ & 8 & 9 & None & $(\text { GATA })_{6-14}$ \\
\hline & & 13 & 12 & & \\
\hline & & & 14 & & \\
\hline \multirow[t]{2}{*}{ D8S1179 } & $8 \mathrm{q} 24.13$ & 11 & 13 & None & $(\mathrm{TCTA})_{7-12}$ \\
\hline & & & 14 & & \\
\hline \multirow[t]{2}{*}{ TH01 } & $11 \mathrm{p} 15.5$ & 9 & 6 & None & $(\mathrm{AATG})_{3-12}$ \\
\hline & & 9.3 & 7 & & \\
\hline \multirow[t]{4}{*}{ vWA } & $12 \mathrm{p} 13.31$ & 14 & $(17)$ & $\mathrm{m}$ & TCTA TCTG TCTA $(\text { TCTG })_{4}(\text { TCTA })_{3}$ \\
\hline & & 20 & 18 & & \\
\hline & & & 20 & & \\
\hline & & & 22 & & \\
\hline \multirow[t]{2}{*}{ D13S317 } & $13 q 31.1$ & 12 & 10 & $\mathrm{~m}$ & $(\text { TATC })_{7-15}$ \\
\hline & & & 12 & & \\
\hline \multirow[t]{2}{*}{ D16S539 } & $16 \mathrm{q} 24.1$ & 10 & 10 & $\mathrm{~m}$ & $(\mathrm{GATA})_{5-15}$ \\
\hline & & 11 & 14 & & \\
\hline \multirow[t]{3}{*}{ D18S51 } & $18 \mathrm{q} 21.33$ & 16 & 14 & None & $(\mathrm{AGAA})_{8-27}$ \\
\hline & & 20 & 17 & & \\
\hline & & & 18 & & \\
\hline \multirow[t]{3}{*}{ D19S433 } & $19 \mathrm{q} 12$ & 12 & 14 & $\mathrm{~m}$ & $(\mathrm{AAGG})(\mathrm{AAAG})(\mathrm{AAGG})(\mathrm{TAGG})(\mathrm{AAGG})_{7-12}$ \\
\hline & & (13) & 15 & & \\
\hline & & 14 & & & \\
\hline \multirow[t]{4}{*}{ D21S11 } & $21 \mathrm{q} 21.1$ & 30 & 28 & $\mathrm{~m}$ & $(\mathrm{TCTA})_{4}(\mathrm{TCTG})_{6}(\mathrm{TCTA})_{3} \mathrm{TA}(\mathrm{TCTA})_{3} \mathrm{TCA}(\mathrm{TCTA})_{2} \mathrm{TCCATA}(\mathrm{TCTA})_{6}$ \\
\hline & & & 30 & & \\
\hline & & & 33.2 & & \\
\hline & & & 34.2 & & \\
\hline
\end{tabular}

M: Complete match, m:partial match, None: no match of genotypes. *Denotes STR loci analyzed by topoisomerase 1 (TOP1) DNA cleavage assay; aNumbers in brackets indicate a minor peak; bSubscripts indicate number of repeat units. A more detailed allele listing of these STR loci is available at www.cstl.nist.gov/biotech/strbase/fr_fact.htm.

The AmpFISTR ${ }^{(\mathbb{R})}$ Identifiler PCR Amplification tests STR alleles (tetra-nucleotide repeats) at 15 loci that are located on distinct chromosomes, behave according to known principles of population genetics and contain low mutation rates [reviewed in (91)]. The results from the STR profiling analysis of RPMI-8402 and CPT-K5 cells are summarized in Table VI.
A comparison of the STR results of the two cell lines shows that it is only the TPOX locus which has a complete match, with the homozygous STR allele bearing the eight repeat units present in both cell lines. For the remaining 14 STR loci, there was either a partial match (D2S1338, D3S1358, D5S818, CSF1PO, vWA, D13S317, D16S539, D19S433, D21S11) or 

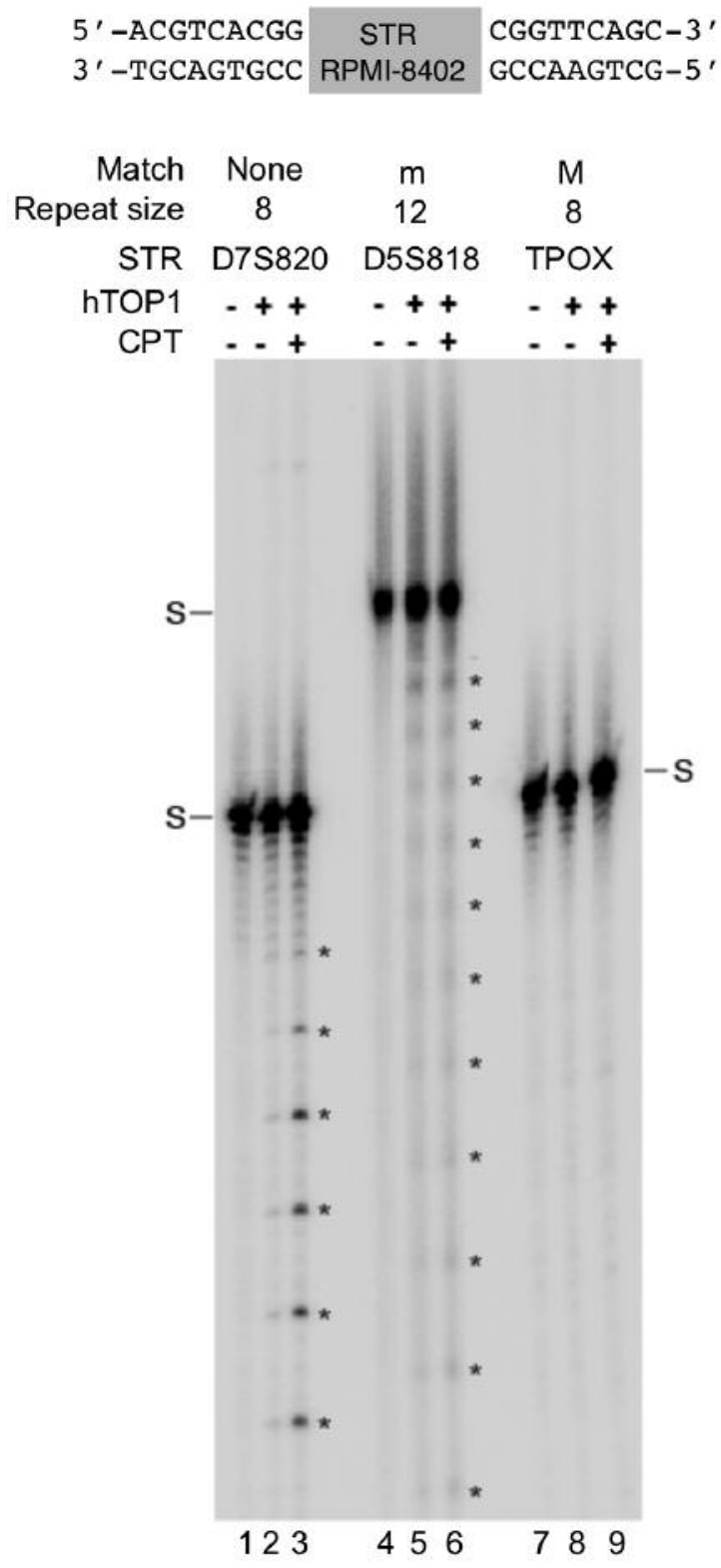

Figure 8. Topoisomerase 1 (TOP1) DNA cleavage assay using short tandem repeat (STR) sequences as DNA substrate. The top panel shows the construction of the double-stranded oligonucleotide substrates. The grey box indicate the double-stranded STR alleles representing no match (None) D7S820, a partial match $(m)$ D5S818, and a complete match $(M)$ for thyroxin peroxidase (TPOX) as observed in the STR profiling of DNA from RPMI-8402 and CPT-K5 cell lines. These oligonucleotides were constructed so that the sequence of each of the three selected RPMI-8402 STR alleles were flanked by a common sequence identical in the three different substrates. Each construct was 5'-radiolabeled and subjected to human topoisomerase 1 (hTOP1) DNA cleavage with purified recombinant hTOP1 in the absence and presence of CPT before the products were separated by $12 \%$ polyacrylamide gel electrophoresis. Lanes 1, 4 and 7: incubation without enzyme and CPT; lanes 2, 5 and 8: incubation with hTOP1 in the absence of CPT; lanes 3, 6 and 9: incubation with hTOP1 and $10 \mu M$ CPT. Uncleaved substrates are marked $(S)$ and $*$ denotes hTOP1 DNA cleavage sites. no match (FGA, D7S820, D8S1179, TH01, D18S51) of the STR alleles between the two cell lines. The aberrant STR loci did not correlate with the observed differences in translocations or breakpoints as identified by karyotyping or genomic profiling. The total number of STR alleles increased from 26 in the RPMI-8402 cells to 42 in the CPT-K5 cell line $(p<0.01)$, which is in line with the observed number of changes by karyotyping and by breakpoints identified by oligo-based aCGH analysis. These findings are in agreement with the fact that CPT induces genomic instability.

STRs can be cleaved in vitro by TOPI and DNA cleavage can be stimulated by CPT. The most obvious conclusion from the STR data is that either the two cell lines are not related or alternatively that differences may be the result of CPT-induced DNA damage and repair.

To test whether STR alleles are targets for CPT-induced DNA damage, we performed a number of classical in vitro TOP1 DNA cleavage experiments in the presence and absence of the drug (Figure 8). We found that the substrate containing the sequence of the D7S820 locus was a stronger TOP1 DNA cleavage site than the substrate containing the sequence for the D5S818 locus in the absence of CPT. Addition of CPT to the TOP1 cleavage reaction resulted in very strong stimulation of DNA cleavage of the D7S820 STR substrate, whereas only very weak stimulation for the D5S818 STR substrate was observed. In contrast, the TPOX STR substrate was not cleaved by TOP1 and neither was cleavage stimulated by CPT.

Correlating these findings with the observed STR allelic differences between the two cell lines, it should be noted that the TPOX STR was the only allele that showed a complete match in the STR profiling and that we found only one allele in both cell lines. This finding indicates that because the TPOX STR does not contain a TOP1 cleavage site it is stable in the presence of CPT. Furthermore, the D7S820 locus, which did not exhibit any match in the STR profiling, contained the strongest TOP1 DNA cleavage site. This site was also the site with the strongest cleavage stimulation by CPT of the three loci sequences tested. Taken together, our findings indicate that the genomic stability of the tested STR alleles depends upon their ability to be cleaved by TOP1 and how strongly CPT can enhance this cleavage. This interpretation is in agreement with the studies on transcription-induced trinucleotide STR instability (92-94). Another way STR can become unstable or mutate is by replication strand slippage or misalignment (95). Replication fork collapse or arrest is one source of DNA strand slippage and as CPT greatly enhances the frequency of replication fork arrests, it is not unlikely that it will affect the STRs as exemplified by the tetra-nucleotides we examined. Normally the rate of slippage is highest in dinucleotide STRs and lowest in tetra-nucleotides but how CPT affects the rate of slippage remains unknown (96). 
In conclusion, it is highly likely that cells subjected to continuous sublethal concentrations of CPT acquire increased STR instability, but further studies focusing on CPT and STR are warranted.

\section{Conclusion}

A major clinical problem is that initially responding patients with cancer treated with CPT or its derivatives gradually acquire resistance. We used the stably and highly CPTresistant cell line CPT-K5 to obtain global genomic insight into acquired CPT resistance by characterizing the cell line, and its parental, using 24-color karyotyping and subtractive oligo-based aCGH analysis.

Although many human cell lines resistant to CPT or its derivatives have been developed, only very few of these have been examined at the chromosomal or genomic level. This is intriguing because CPT is a specific inhibitor of TOP1, which has a major role in DNA metabolism, such as in transcription, replication, recombination and repair.

By 24-color karyotyping, we showed that CPT-K5 is hypotetraploid with a modal chromosomal number reduced to 80 , and had loss or gain of 18 structural aberrant chromosomes compared with its parental RPMI-8402. Subtractive oligobased aCGH analysis identified 165 copy number alterations and 236 unbalanced DNA breakpoints unevenly distributed across the chromosomal complement in CPT-K5 cells. Furthermore, we found that STRs highly differ between CPTK5 and its parental cell line, and we show for the first time that STRs are TOP1 targets that can be differentially stimulated by CPT. These findings are in agreement with repair pathways that efficiently repaired CPT-induced DNA damage at the expense of conserved genome integrity providing substantial chromosomal and genomic alterations that may have been beneficial for survival and cellular proliferation. However, further studies are needed to establish whether STR alterations actually contribute to cellular tolerance to CPT.

We suggest that acquired resistance to CPT in the CPT-K5 cell line is a multifactorial process. Four major mechanisms seem to be involved in addition to its acquired previously described TOP1 mutation. These are: i) reduced gene dosage of $T O P 1$ resulting in decreased cellular amount and activity of the enzyme; ii) high amplification of $A B C G 2$, which may contribute to reduced intracellular concentration of active drug by decreased drug influx/increased drug efflux; iii) no copy number changes in TP53 and BIRC5 genes, which may contribute to resistance to apoptosis; and iv) high amplification of TDP 1 accompanied by increased TDP1 activity and reduced gene dosage of PTEN, which were recently shown to be of great importance for repair of CPT-induced DNA damage.

CPT-resistant cell lines have variable degrees of resistance to CPT and variable dependency on the presence of CPT to retain their resistance to it. These observations may relate to mechanisms implicated in their resistance. Only a few CPTresistant cell lines have been examined at the genomic level, and clearly, more CPT-resistant cell lines need to be examined with up-to-date genomic methods in order to enhance the understanding of their resistance mechanisms. Furthermore, it should be kept in mind that CPT-resistant cell lines are developed by exposure to longitudinal increments of sublethal drug doses, and often prior to their selection, had a mutagenic step, which may provide the cells with potential initial genomic aberrations amenable to selective advantage. This is different to the clinical situation in that patients becoming resistant to treatment with CPT-derived drugs did not have an initial mutagenic step and most often no increment in drug dose.

Nevertheless, identification of recurrent regions implicated in the acquisition of CPT resistance might provide the first clues to identifying important regions of the genome, and consequently genes, which could serve as potential therapeutic targets for intervention against development of CPT resistance, or for its reversal.

\section{Conflicts of Interest}

The Authors declare no conflicts of interest in regard to this study.

\section{Acknowledgements}

The biotechnologists Bente Madsen and Pia Kristensen are greatly thanked for excellent technical assistance. Technician Noriko Hansen is thanked for purification of human TOP1. Dr. Christopher Veigaard is greatly thanked for providing cell growth characteristics. The Danish Cancer Society supported the study.

\section{References}

1 Kantarjian HM, Beran M, Ellis A, Zwelling L, O'Brien S, Cazenave L, Koller C, Rios MB, Plunkett W and Keating MJ: Phase I study of Topotecan, a new topoisomerase I inhibitor, in patients with refractory or relapsed acute leukemia. Blood 81 : 1146-1151, 1993.

2 Smith DH, Adams JR, Johnston SR, Gordon A, Drummond MF and Bennett CL: A comparative economic analysis of pegylated liposomal doxorubicin versus topotecan in ovarian cancer in the USA and the UK. Ann Oncol 13: 1590-1597, 2002.

3 Tsavaris N, Kosmas C, Skopelitis H, Papadoniou N, Polyzos A, Zografos G, Adoniou E, Gryniatsos J, Felekouras E, Zacharakis M, Sigala F, Bacoyiannis C, Papastratis G and Papalambros E: Sequential administration of 5-fluorouracil (5FU)/leucovorin (LV) followed by irinotecan (CPT-11) at relapse versus CPT-11 followed by 5 -FU/LV in advanced colorectal carcinoma. A phase III randomized study. Chemotherapy 53: 282-291, 2007.

4 Riemsma R, Simons JP, Bashir Z, Gooch CL and Kleijnen J: Systematic Review of topotecan (Hycamtin) in relapsed small cell lung cancer. BMC Cancer 10: 436, 2010.

5 Douillard JY, Cunningham D, Roth AD, Navarro M, James RD, Karasek P, Jandik P, Iveson T, Carmichael J, Alakl M, Gruia G, Awad L and Rougier P: Irinotecan combined with fluorouracil 
compared with fluorouracil alone as first-line treatment for metastatic colorectal cancer: a multicentre randomised trial. Lancet 355: 1041-1047, 2000.

6 Beretta GL, Gatti L, Perego P and Zaffaroni N: Camptothecin resistance in cancer: insights into the molecular mechanisms of a DNA-damaging drug. Curr Med Chem 20: 1541-1565, 2013.

7 Pommier Y: Topoisomerase I inhibitors: camptothecins and beyond. Nat Rev Cancer 6: 789-802, 2006.

8 Wang JC: Cellular roles of DNA topoisomerases: a molecular perspective. Nat Rev Mol Cell Biol 3: 430-440, 2002.

9 Rossi F, Labourier E, Forne T, Divita G, Derancourt J, Riou JF, Antoine E, Cathala G, Brunel $\mathrm{C}$ and Tazi J: Specific phosphorylation of SR proteins by mammalian DNA topoisomerase I. Nature 381: 80-82, 1996.

10 Pfister TD, Reinhold WC, Agama K, Gupta S, Khin SA, Kinders RJ, Parchment RE, Tomaszewski JE, Doroshow JH and Pommier Y: Topoisomerase I levels in the NCI-60 cancer cell line panel determined by validated ELISA and microarray analysis and correlation with indenoisoquinoline sensitivity. Mol Cancer Ther 8: 1878-1884, 2009.

11 Andoh T, Ishii K, Suzuki Y, Ikegami Y, Kusunoki Y, Takemoto $\mathrm{Y}$ and Okada K: Characterization of a mammalian mutant with a camptothecin-resistant DNA topoisomerase I. Proc Natl Acad Sci USA 84: 5565-5569, 1987.

12 Kanzawa F, Sugimoto Y, Minato K, Kasahara K, Bungo M, Nakagawa K, Fujiwara Y, Liu LF and Saijo N: Establishment of a camptothecin analogue (CPT-11)-resistant cell line of human non-small cell lung cancer: characterization and mechanism of resistance. Cancer Res 50: 5919-5924, 1990.

13 Kubota N, Kanzawa F, Nishio K, Takeda Y, Ohmori T, Fujiwara Y, Terashima Y and Saijo N: Detection of topoisomerase I gene point mutation in CPT-11 resistant lung cancer cell line. Biochem Biophys Res Commun 188: 571-577, 1992.

14 Sugimoto Y, Tsukahara S, Oh-hara T, Isoe T and Tsuruo T: Decreased expression of DNA topoisomerase I in camptothecinresistant tumor cell lines as determined by a monoclonal antibody. Cancer Res 50: 6925-6930, 1990.

15 Rubin E, Pantazis P, Bharti A, Toppmeyer D, Giovanella B and Kufe D: Identification of a mutant human topoisomerase I with intact catalytic activity and resistance to 9-nitro-camptothecin. J Biol Chem 269: 2433-2439, 1994.

16 Fujimori A, Harker WG, Kohlhagen G, Hoki Y and Pommier Y: Mutation at the catalytic site of topoisomerase I in CEM/C2, a human leukemia cell line resistant to camptothecin. Cancer Res 55: 1339-1346, 1995.

17 Chatterjee D, Wyche JH and Pantazis P: Induction of apoptosis in malignant and camptothecin-resistant human cells. Ann N Y Acad Sci 803: 143-156, 1996.

18 Urasaki Y, Laco GS, Pourquier P, Takebayashi Y, Kohlhagen G, Gioffre C, Zhang H, Chatterjee D, Pantazis P and Pommier Y: Characterization of a novel topoisomerase I mutation from a camptothecin-resistant human prostate cancer cell line. Cancer Res 61: 1964-1969, 2001.

19 Saleem A, Ibrahim N, Patel M, Li XG, Gupta E, Mendoza J, Pantazis P and Rubin EH: Mechanisms of resistance in a human cell line exposed to sequential topoisomerase poisoning. Cancer Res 57: 5100-5106, 1997.

20 Chang JY, Liu JF, Juang SH, Liu TW and Chen LT: Novel mutation of topoisomerase I in rendering cells resistant to camptothecin. Cancer Res 62: 3716-3721, 2002.
21 Gao K, Lockwood WW, Li J, Lam W and Li G: Genomic analyses identify gene candidates for acquired irinotecan resistance in melanoma cells. Int J Oncol 32: 1343-1349, 2008.

22 Petitprez A, Poindessous V, Ouaret D, Regairaz M, Bastian G, Guerin E, Escargueil AE and Larsen AK: Acquired irinotecan resistance is accompanied by stable modifications of cell cycle dynamics independent of MSI status. Int J Oncol 42: 16441653, 2013.

23 Tuduri S, Crabbe L, Conti C, Tourriere H, Holtgreve-Grez H, Jauch A, Pantesco V, De Vos J, Thomas A, Theillet C, Pommier Y, Tazi J, Coquelle A and Pasero P: Topoisomerase I suppresses genomic instability by preventing interference between replication and transcription. Nat Cell Biol 11: 1315-1324, 2009.

24 Kjeldsen E, Bonven BJ andoh T, Ishii K, Okada K, Bolund L and Westergaard O: Characterization of a camptothecinresistant human DNA topoisomerase I. J Biol Chem 263: 39123916, 1988.

25 Roy A, Tesauro C, Frohlich R, Hede MS, Nielsen MJ, Kjeldsen E, Bonven B, Stougaard M, Gromova I and Knudsen BR: Decreased camptothecin sensitivity of the stem-cell-like fraction of $\mathrm{Caco} 2$ cells correlates with an altered phosphorylation pattern of topoisomerase I. PloS One 9: e99628, 2014.

26 Jensen PW, Falconi M, Kristoffersen EL, Simonsen AT, Cifuentes JB, Marcussen LB, Frohlich R, Vagner J, Harmsen C, Juul S, Ho YP, Withers MA, Lupski JR, Koch J, Desideri A, Knudsen BR and Stougaard M: Real-time detection of TDP1 activity using a fluorophore-quencher coupled DNA-biosensor. Biosens Bioelectron 48: 230-237, 2013.

27 Lisby M, Krogh BO, Boege F, Westergaard O and Knudsen BR: Camptothecins inhibit the utilization of hydrogen peroxide in the ligation step of topoisomerase I catalysis. Biochemistry 37 : 10815-10827, 1998.

28 Veigaard $\mathrm{C}$ and Kjeldsen E: Exploring the genome-wide relation between copy number status and microRNA expression. Genomics 104: 271-278, 2014.

29 ISCN: An International System for Human Cytogenetic Nomenclature (2013). Shaffer LG, McGowan-Jordan and Schmid M (Eds.) Basel: S. Karger and Cytogenetic and Genome Research, 2013.

30 Kerndrup GB and Kjeldsen E: Acute leukemia cytogenetics: an evaluation of combining G-band karyotyping with multi-color spectral karyotyping. Cancer Genet Cytogenet 124: 7-11, 2001.

31 Kjeldsen $\mathrm{E}$ and Roug AS: A novel unbalanced de novo translocation $\operatorname{der}(5) \mathrm{t}(4 ; 5)(\mathrm{q} 26 ; \mathrm{q} 21.1)$ in adult T-cell precursor lymphoblastic leukemia. Mol Cytogenet 5: 21, 2012.

32 Braylan RC, Orfao A, Borowitz MJ and Davis BH: Optimal number of reagents required to evaluate hematolymphoid neoplasias: results of an international consensus meeting. Cytometry 46: 23-27, 2001.

33 Christiansen K, Svejstrup AB andersen AH and Westergaard O: Eukaryotic topoisomerase I-mediated cleavage requires bipartite DNA interaction. Cleavage of DNA substrates containing strand interruptions implicates a role for topoisomerase $\mathrm{I}$ in illegitimate recombination. J Biol Chem 268: 9690-9701, 1993.

34 Tamura H, Kohchi C, Yamada R, Ikeda T, Koiwai O, Patterson E, Keene JD, Okada K, Kjeldsen E, Nishikawa K and Andoh $\mathrm{T}$ : Molecular cloning of a cDNA of a camptothecin-resistant human DNA topoisomerase I and identification of mutation sites. Nucleic Acids Res 19: 69-75, 1991. 
35 Stougaard M, Lohmann JS, Mancino A, Celik S, Andersen FF, Koch J and Knudsen BR: Single-molecule detection of human topoisomerase I cleavage-ligation activity. ACS Nano 3: 223233, 2009.

36 Andersen FF, Stougaard M, Jorgensen HL, Bendsen S, Juul S, Hald $\mathrm{K}$ andersen AH, Koch J and Knudsen BR: Multiplexed detection of site specific recombinase and DNA topoisomerase activities at the single molecule level. ACS Nano 3: 4043-4054, 2009.

37 Huang CC, Hou Y, Woods LK, Moore GE and Minowada J: Cytogenetic study of human lymphoid T-cell lines derived from lymphocytic leukemia. J Natl Cancer Inst 53: 655-660, 1974.

38 Hayata I, Oshimura M, Minowada J and Sandberg AA: Chromosomal banding of cultured $\mathrm{T}$ and B lymphocytes. In Vitro 11: 361-368, 1975.

39 Le Beau MM, McKeithan TW, Shima EA, Goldman-Leikin RE, Chan SJ, Bell GI, Rowley JD and Diaz MO: T-cell receptor alpha-chain gene is split in a human T-cell leukemia cell line with a $\mathrm{t}(11 ; 14)(\mathrm{p} 15 ; \mathrm{q} 11)$. Proc Natl Acad Sci USA 83: 97449748, 1986.

40 McGuire EA, Hockett RD, Pollock KM, Bartholdi MF, O'Brien SJ and Korsmeyer SJ: The $\mathrm{t}(11 ; 14)(\mathrm{p} 15 ; \mathrm{q} 11)$ in a T-cell acute lymphoblastic leukemia cell line activates multiple transcripts, including Ttg-1, a gene encoding a potential zinc finger protein. Mol Cell Biol 9: 2124-2132, 1989.

41 Kjeldsen E, Tordrup D, Hubner GM, Knudsen BR and Andersen FF: Topoisomerase I deficiency results in chromosomal alterations in cervical cancer cells. Anticancer Res 30: 3257-3265, 2010.

42 Salido M, Arriola E, Carracedo A, Canadas I, Rovira A, Espinet B, Rojo F, Arumi M, Serrano S, Albanell J and Sole F: Cytogenetic characterization of NCI-H69 and NCI-H69AR small cell lung cancer cell lines by spectral karyotyping. Cancer Genet Cytogenet 191: 97-101, 2009.

43 Rao VK, Wangsa D, Robey RW, Huff L, Honjo Y, Hung J, Knutsen T, Ried T and Bates SE: Characterization of ABCG2 gene amplification manifesting as extrachromosomal DNA in mitoxantrone-selected SF295 human glioblastoma cells. Cancer Genet Cytogenet 160: 126-133, 2005.

44 Yasui K, Mihara S, Zhao C, Okamoto H, Saito-Ohara F, Tomida A, Funato T, Yokomizo A, Naito S, Imoto I, Tsuruo T and Inazawa J: Alteration in copy numbers of genes as a mechanism for acquired drug resistance. Cancer Res 64: 1403-1410, 2004.

45 Veigaard $\mathrm{C}$ and Kjeldsen E: microRNA global expression analysis and genomic profiling of the camptothecin-resistant TALL derived cell line CPT-K5. RNA Dis 1: 12, 2014.

46 Przybytkowski E, Lenkiewicz E, Barrett MT, Klein K, Nabavi $\mathrm{S}$, Greenwood $\mathrm{CM}$ and Basik M: Chromosome-breakage genomic instability and chromothripsis in breast cancer. BMC Genomics 15: 579, 2014.

47 Jones MJ and Jallepalli PV: Chromothripsis: chromosomes in crisis. Dev Cell 23: 908-917, 2012.

48 Kloosterman WP, Hoogstraat M, Paling O, Tavakoli-Yaraki M, Renkens I, Vermaat JS, van Roosmalen MJ, van Lieshout S, Nijman IJ, Roessingh W, van 't Slot R, van de Belt J, Guryev V, Koudijs M, Voest E and Cuppen E: Chromothripsis is a common mechanism driving genomic rearrangements in primary and metastatic colorectal cancer. Genome Biol 12: R103, 2011.

49 Lapuk AV, Wu C, Wyatt AW, McPherson A, McConeghy BJ, Brahmbhatt S, Mo F, Zoubeidi A anderson S, Bell RH, Haegert
A, Shukin R, Wang Y, Fazli L, Hurtado-Coll A, Jones EC, Hach F, Hormozdiari F, Hajirasouliha I, Boutros PC, Bristow RG, Zhao Y, Marra MA, Fanjul A, Maher CA, Chinnaiyan AM, Rubin MA, Beltran H, Sahinalp SC, Gleave ME, Volik SV and Collins CC: From sequence to molecular pathology and a mechanism driving the neuroendocrine phenotype in prostate cancer. J Pathol 227: 286-297, 2012.

50 Magrangeas F, Avet-Loiseau H, Munshi NC and Minvielle S: Chromothripsis identifies a rare and aggressive entity among newly diagnosed multiple myeloma patients. Blood 118: 675678, 2011.

51 Molenaar JJ, Koster J, Zwijnenburg DA, van Sluis P, Valentijn LJ, van der Ploeg I, Hamdi M, van Nes J, Westerman BA, van Arkel J, Ebus ME, Haneveld F, Lakeman A, Schild L, Molenaar P, Stroeken P, van Noesel MM, Ora I, Santo EE, Caron HN, Westerhout EM and Versteeg R: Sequencing of neuroblastoma identifies chromothripsis and defects in neuritogenesis genes. Nature 483: 589-593, 2012.

52 Rausch T, Jones DT, Zapatka M, Stutz AM, Zichner T, Weischenfeldt J, Jager N, Remke M, Shih D, Northcott PA, Pfaff E, Tica J, Wang Q, Massimi L, Witt H, Bender S, Pleier $\mathrm{S}$, Cin H, Hawkins C, Beck C, von Deimling A, Hans V, Brors B, Eils R, Scheurlen W, Blake J, Benes V, Kulozik AE, Witt O, Martin D, Zhang C, Porat R, Merino DM, Wasserman J, Jabado N, Fontebasso A, Bullinger L, Rucker FG, Dohner K, Dohner H, Koster J, Molenaar JJ, Versteeg R, Kool M, Tabori U, Malkin D, Korshunov A, Taylor MD, Lichter P, Pfister SM and Korbel JO: Genome sequencing of pediatric medulloblastoma links catastrophic DNA rearrangements with TP53 mutations. Cell 148: 59-71, 2012.

53 Rasheed ZA and Rubin EH: Mechanisms of resistance to topoisomerase I-targeting drugs. Oncogene 22: 7296-7304, 2003.

54 Rubin EH, Li TK, Duann P and Liu LF: Cellular resistance to topoisomerase poisons. Cancer Treat and Res 87: 243-260, 1996.

55 Liao Z, Robey RW, Guirouilh-Barbat J, To KK, Polgar O, Bates SE and Pommier Y: Reduced expression of DNA topoisomerase I in SF295 human glioblastoma cells selected for resistance to homocamptothecin and diflomotecan. Mol Pharmacol 73: 490497, 2008.

56 Pommier Y, Pourquier P, Urasaki Y, Wu J and Laco GS: Topoisomerase I inhibitors: selectivity and cellular resistance. Drug Resist Updat 2: 307-318, 1999.

57 Chrencik JE, Staker BL, Burgin AB, Pourquier P, Pommier Y, Stewart L and Redinbo MR: Mechanisms of camptothecin resistance by human topoisomerase I mutations. J Mol Biol 339: 773-784, 2004.

58 Mo W and Zhang JT: Human ABCG2: structure, function and its role in multidrug resistance. Int J Biochem Mol Biol 3: 127, 2012.

59 Hoki Y, Fujimori A and Pommier Y: Differential cytotoxicity of clinically important camptothecin derivatives in P-glycoproteinoverexpressing cell lines. Cancer Chemother Pharmacol 40: 433-438, 1997.

60 Brangi M, Litman T, Ciotti M, Nishiyama K, Kohlhagen G, Takimoto C, Robey R, Pommier Y, Fojo T and Bates SE: Camptothecin resistance: role of the ATP-binding cassette $(\mathrm{ABC})$, mitoxantrone-resistance half-transporter (MXR) and potential for glucuronidation in MXR-expressing cells. Cancer Res 59: 5938-5946, 1999. 
61 Rajendra R, Gounder MK, Saleem A, Schellens JH, Ross DD, Bates SE, Sinko P and Rubin EH: Differential effects of the breast cancer resistance protein on the cellular accumulation and cytotoxicity of 9-aminocamptothecin and 9nitrocamptothecin. Cancer Res 63: 3228-3233, 2003.

62 Ross DD, Yang W, Abruzzo LV, Dalton WS, Schneider E, Lage H, Dietel M, Greenberger L, Cole SP and Doyle LA: Atypical multidrug resistance: breast cancer resistance protein messenger RNA expression in mitoxantrone-selected cell lines. J Natl Cancer Inst 91: 429-433, 1999.

63 Candeil L, Gourdier I, Peyron D, Vezzio N, Copois V, Bibeau F, Orsetti B, Scheffer GL, Ychou M, Khan QA, Pommier Y, Pau B, Martineau P and Del Rio M: ABCG2 overexpression in colon cancer cells resistant to SN38 and in irinotecan-treated metastases. Int J Cancer 109: 848-854, 2004.

$64 \mathrm{Su} \mathrm{Y,} \mathrm{Lee} \mathrm{SH} \mathrm{and} \mathrm{Sinko} \mathrm{PJ:} \mathrm{Inhibition} \mathrm{of} \mathrm{efflux} \mathrm{transporter}$ ABCG2/BCRP does not restore mitoxantrone sensitivity in irinotecan-selected human leukemia CPT-K5 cells: evidence for multifactorial multidrug resistance. Eur J Pharm Sci 29: 102110, 2006.

65 Bates SE, Medina-Perez WY, Kohlhagen G, Antony S, Nadjem T, Robey RW and Pommier Y: ABCG2 mediates differential resistance to $\mathrm{SN}-38$ (7-ethyl-10-hydroxycamptothecin) and homocamptothecins. J Pharmacol Exp Ther 310: 836-842, 2004

66 Maliepaard M, van Gastelen MA, de Jong LA, Pluim D, van Waardenburg RC, Ruevekamp-Helmers MC, Floot BG and Schellens JH: Overexpression of the BCRP/MXR/ABCP gene in a topotecan-selected ovarian tumor cell line. Cancer Res 59: 4559-4563, 1999.

67 Kawabata S, Oka M, Shiozawa K, Tsukamoto K, Nakatomi K, Soda H, Fukuda M, Ikegami Y, Sugahara K, Yamada Y, Kamihira S, Doyle LA, Ross DD and Kohno S: Breast cancer resistance protein directly confers $\mathrm{SN}-38$ resistance of lung cancer cells. Biochem Biophys Res Commun 280: 1216-1223, 2001.

68 Tomicic MT and Kaina B: Topoisomerase degradation, DSB repair, p53 and IAPs in cancer cell resistance to camptothecinlike topoisomerase I inhibitors. Biochim Biophys Acta 1835: 11-27, 2013.

69 Nieves-Neira W and Pommier Y: Apoptotic response to camptothecin and 7-hydroxystaurosporine $(\mathrm{UCN}-01)$ in the 8 human breast cancer cell lines of the NCI Anticancer Drug Screen: multifactorial relationships with topoisomerase I, protein kinase $\mathrm{C}, \mathrm{Bcl}-2, \mathrm{p} 53$, MDM-2 and caspase pathways. Int J Cancer 82: 396-404, 1999.

70 Roos WP and Kaina B: DNA damage-induced cell death by apoptosis. Trends Mol Med 12: 440-450, 2006.

71 Dubrez L, Goldwasser F, Genne P, Pommier Y and Solary E: The role of cell cycle regulation and apoptosis triggering in determining the sensitivity of leukemic cells to topoisomerase I and II inhibitors. Leukemia 9: 1013-1024, 1995.

72 Solary E, Dubrez L, Eymin B, Bertrand R and Pommier Y: Apoptosis of human leukemic cells induced by topoisomerase I and II inhibitors. Bull Cancer 83: 205-212, 1996.

73 Beretta GL, Perego P and Zunino F: Targeting topoisomerase I: molecular mechanisms and cellular determinants of response to topoisomerase I inhibitors. Expert Opin Ther Targets 12: 1243-1256, 2008.

74 Pommier Y, Huang SY, Gao R, Das BB, Murai J and Marchand C: Tyrosyl-DNA-phosphodiesterases (TDP1 and TDP2). DNA Repair (Amst) 19: 114-129, 2014.
75 Desai SD, Liu LF, Vazquez-Abad D and D'Arpa P: Ubiquitindependent destruction of topoisomerase I is stimulated by the antitumor drug camptothecin. J Biol Chem 272: 24159-24164, 1997.

76 Takahata C, Masuda Y, Takedachi A, Tanaka K, Iwai S and Kuraoka I: Repair synthesis step involving ERCC1-XPF participates in DNA repair of the Top1-DNA damage complex. Carcinogenesis 36: 841-851, 2015.

77 Takashima H, Boerkoel CF, John J, Saifi GM, Salih MA, Armstrong D, Mao Y, Quiocho FA, Roa BB, Nakagawa M, Stockton DW and Lupski JR: Mutation of TDP1, encoding a topoisomerase I-dependent DNA damage repair enzyme, in spinocerebellar ataxia with axonal neuropathy. Nat Genet 32: 267-272, 2002.

78 Das BB, Huang SY, Murai J, Rehman I, Ame JC, Sengupta S, Das SK, Majumdar P, Zhang H, Biard D, Majumder HK, Schreiber V and Pommier Y: PARP1-TDP1 coupling for the repair of topoisomerase I-induced DNA damage. Nucleic Acids Res 42: 4435-4449, 2014.

79 Ando K, Shah AK, Sachdev V, Kleinstiver BP, Taylor-Parker J, Welch MM, Hu Y, Salgia R, White FM, Parvin JD, Ozonoff A, Rameh LE, Joung JK and Bharti AK: Camptothecin resistance is determined by the regulation of topoisomerase I degradation mediated by ubiquitin proteasome pathway. Oncotarget 8 : 43733-43751, 2017.

80 Yamauchi T, Yoshida A and Ueda T: Camptothecin induces DNA strand breaks and is cytotoxic in stimulated normal lymphocytes. Oncol Rep 25: 347-352, 2011.

81 Sakofsky CJ, Ayyar S and Malkova A: Break-induced replication and genome stability. Biomolecules 2: 483-504, 2012.

82 Leffak M: Break-induced replication links microsatellite expansion to complex genome rearrangements. Bioessays 39(8): 2017. doi: 10.1002/bies.201700025.

83 Hastings PJ, Ira G and Lupski JR: A microhomologymediated break-induced replication model for the origin of human copy number variation. PLoS Genet 5: e1000327, 2009.

84 Reyes GX, Schmidt TT, Kolodner RD and Hombauer H: New insights into the mechanism of DNA mismatch repair. Chromosoma 124: 443-462, 2015.

85 Li GM: Mechanisms and functions of DNA mismatch repair. Cell Res 18: 85-98, 2008.

86 Gomes-Pereira M, Fortune MT, Ingram L, McAbney JP and Monckton DG: Pms2 is a genetic enhancer of trinucleotide CAG.CTG repeat somatic mosaicism: implications for the mechanism of triplet repeat expansion. Hum Mol Genet 13: 1815-1825, 2004.

87 Pichierri P, Franchitto A, Piergentili R, Colussi C and Palitti F: Hypersensitivity to camptothecin in MSH2 deficient cells is correlated with a role for MSH2 protein in recombinational repair. Carcinogenesis 22: 1781-1787, 2001.

88 Xiao Z, Chen Z, Gunasekera AH, Sowin TJ, Rosenberg SH, Fesik S and Zhang H: Chk1 mediates S and G2 arrests through Cdc25A degradation in response to DNA-damaging agents. J Biol Chem 278: 21767-21773, 2003.

89 Nims RW, Sykes G, Cottrill K, Ikonomi P and Elmore E: Short tandem repeat profiling: part of an overall strategy for reducing the frequency of cell misidentification. In Vitro Cell Dev Biol Anim 46: 811-819, 2010 
90 Kerrigan L and Nims RW: Authentication of human cell-based products: the role of a new consensus standard. Regen Med 6: 255-260, 2011

91 Butler JM: Genetics and genomics of core short tandem repeat loci used in human identity testing. J Forensic Sci 51: 253-265, 2006.

92 Hubert L, Jr., Lin Y, Dion V and Wilson JH: Topoisomerase 1 and single-strand break repair modulate transcription-induced CAG repeat contraction in human cells. Mol Cell Biol 31: 3105-3112, 2011.

93 Lin Y and Wilson JH: Diverse effects of individual mismatch repair components on transcription-induced $\mathrm{CAG}$ repeat instability in human cells. DNA Repair (Amst) 8: 878-885, 2009.

94 Lin $\mathrm{Y}$ and Wilson $\mathrm{JH}$ : Transcription-induced CAG repeat contraction in human cells is mediated in part by transcriptioncoupled nucleotide excision repair. Mol Cell Biol 27: 62096217, 2007.

95 Kim JC and Mirkin SM: The balancing act of DNA repeat expansions. Curr Opin Genet Dev 23: 280-288, 2013.

96 Yang Z, Lau R, Marcadier JL, Chitayat D and Pearson CE: Replication inhibitors modulate instability of an expanded trinucleotide repeat at the myotonic dystrophy type 1 disease locus in human cells. Am J Hum Genet 73: 1092-1105, 2003.
97 Park SY, Choi HC, Chun YH, Kim H and Park SH: Characterization of chromosomal aberrations in lung cancer cell lines by cross-species color banding. Cancer Genet Cytogenet 124: 62-70, 2001.

98 Shipley JM, Sheppard DM and Sheer D: Karyotypic analysis of the human monoblastic cell line U937. Cancer Genet Cytogenet 30: 277-284, 1988.

99 Pittman SM, Kavallaris $M$ and Stewart BW: Karyotypic analysis of CCRF-CEM and drug-resistant cell lines with stable and unstable ploidy. Cancer Genet Cytogenet 66: 54-62, 1993.

100 Bernardino J, Bourgeois CA, Muleris M, Dutrillaux AM, Malfoy B and Dutrillaux B: Characterization of chromosome changes in two human prostatic carcinoma cell lines (PC-3 and DU145) using chromosome painting and comparative genomic hybridization. Cancer Genet Cytogenet 96: 123-128, 1997.

101 Beheshti B, Park PC, Sweet JM, Trachtenberg J, Jewett MA and Squire JA: Evidence of chromosomal instability in prostate cancer determined by spectral karyotyping (SKY) and interphase fish analysis. Neoplasia 3: 62-69, 2001.

Received November 17, 2017

Revised December 12, 2017

Accepted December 13, 2017 